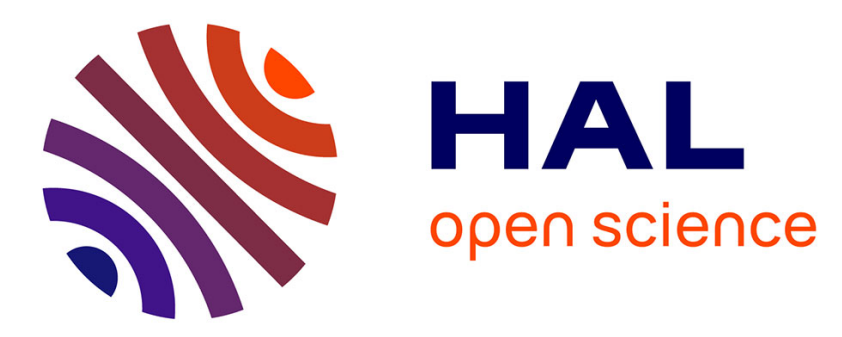

\title{
Acibenzolar-S-methyl and resistance quantitative trait loci complement each other to control apple scab and fire blight
}

Juliette Bénéjam, Elisa Ravon, Matthieu Gaucher, Marie-Noëlle Brisset, Charles-Eric Durel, Laure Perchepied

\section{To cite this version:}

Juliette Bénéjam, Elisa Ravon, Matthieu Gaucher, Marie-Noëlle Brisset, Charles-Eric Durel, et al.. Acibenzolar-S-methyl and resistance quantitative trait loci complement each other to control apple scab and fire blight. Plant Disease, 2020, 105 (6), pp.1702-1710. 10.1094/pdis-07-20-1439-re . hal03034383

\section{HAL Id: hal-03034383 \\ https: / hal.inrae.fr/hal-03034383}

Submitted on 1 Dec 2020

HAL is a multi-disciplinary open access archive for the deposit and dissemination of scientific research documents, whether they are published or not. The documents may come from teaching and research institutions in France or abroad, or from public or private research centers.
L'archive ouverte pluridisciplinaire HAL, est destinée au dépôt et à la diffusion de documents scientifiques de niveau recherche, publiés ou non, émanant des établissements d'enseignement et de recherche français ou étrangers, des laboratoires publics ou privés.

$$
\text { Copyright }
$$


1 Acibenzolar-S-methyl and resistance quantitative trait loci complement each

2 other to control apple scab and fire blight

Juliette Bénéjam, Elisa Ravon, Matthieu Gaucher, Marie-Noëlle Brisset, Charles-Eric

Durel $^{*}$, Laure Perchepied

UMR 1345 Institut de Recherche en Horticulture et Semences (IRHS), INRAE, Université d'Angers, Institut-Agro Agrocampus-Ouest, SFR 4207 QuaSaV, 49071, Beaucouzé, France

${ }^{*}$ Corresponding author: Charles-Eric Durel, charles-eric.durel@inrae.fr

\section{Abstract}

Diversifying disease control methods is a key strategy to sustainably reduce pesticides.

Plant genetic resistance has long been used to create resistant varieties. Plant resistance inducers $(\mathrm{PRI})$ are also considered to promote crop health, but their effectiveness is partial and can vary according to the environment and the plant genotype. We investigated the putative interaction between intrinsic (genetic) and PRIinduced resistance in apple when affected by scab and fire blight diseases. A large F1 mapping population was challenged by each disease after a pre-treatment with acibenzolar-S-methyl (ASM) and compared with the water control. Apple scab and fire blight resistance quantitative trait loci (QTLs) were detected in both conditions and compared. ASM exhibited a strong effectiveness in reducing both diseases. When combined, QTL-controlled and ASM-induced resistance acted complementarily to reduce the symptoms from $85 \%$ to $100 \%$ depending on the disease. In our conditions, resistance QTLs were only slightly or rarely affected by ASM treatment, despite their 
probable implication in various stages of the resistance build-up. Implications of these results are discussed considering already known results, the underlying mechanisms, cross-protection of both types of resistance against pathogen adaptation, and practical application in orchard conditions.

Keywords: Intrinsic resistance, induced defense, Malus domestica, Venturia inaequalis, Erwinia amylovora

\section{Introduction}

Plant diseases threaten global agricultural production, leading to the extensive use of pesticides. Plant genetic resistance is considered as a major lever, and breeding for new resistant varieties is very active in most crop species. However resistance genes exert selection pressures on pathogens, triggering their evolution (McDonald and Linde, 2002). Diversifying and pyramiding resistance genes, especially when controlling both qualitative and quantitative resistance, is considered as a promising approach for achieving durable resistance (Pilet-Nayel et al., 2017). Such diversification is indeed expected to promote conflicting selection pressures on pathogen populations, which should constrain them to an evolutionary compromise limiting their development.

Reduced reliance on conventional pesticides can be also achieved by biocontrol (Pal and McSpadden Gardener, 2006; Burketova et al., 2015). Plant resistance inducers (PRIs, also called elicitors or plant defense activators) are part of biocontrol methods. They include a range of chemical (Bektas and Eulgem, 2015) or biological (Wiesel et al., 2014) stimulators able to activate plant defenses, without direct toxicity against pathogens (Oostendorp et al., 2001; Oliveira et al., 2016). PRls provide most often partial resistance only and their performance are greatly influenced by abiotic and biotic factors including the pathogen and the plant genotype (Walters et al., 2013). However, 
mechanisms underlying these numerous interactions are not clearly understood. Regarding the plant, comprehensive knowledge on genotype-PRI interactions could re-orientate plant breeding programs towards responsive genotypes or assist the choice of varieties to be deployed in practice, especially if PRIs are intended to be used in pest management programs. Combination of genetic resistance with PRIs are expected to multiply selection pressures on pathogen populations and thus limit their evolution, similarly to the combination of genetic resistance.

Apple (Malus domestica) is a major fruit tree species which requires a tremendous amount of pesticides in temperate climate conditions (MacHardy, 1996). Apple genotypes display a great variability of responses to apple scab, caused by the ascomycete fungus Venturia inaequalis and fire blight, caused by the bacterium Erwinia amylovora, two major diseases impacting orchards. Genetic mapping studies revealed numerous $\mathrm{R}$ genes and QTLs involved in resistance against apple scab (summarized in Khajuria et al., 2018) and fire blight (reviewed in Malnoy et al., 2012; Emeriewen et al., 2019), conferring partial to complete resistance to the diseases. Some of these loci are known to be strain-specific, with breakdown of resistance already demonstrated (Parisi, 1993; Caffier et al., 2010, 2015; Wöhner et al., 2014; Peil et al., 2020; Patocchi et al., 2020). The Rvi6 gene, also called Vf from Malus floribunda, was one of the genes most widely used in apple breeding programs but was overcome as early as 1981 by $V$. inaequalis race 6 (Parisi, 1993). In apple, as in most plant species, quantitative resistance is considered more durable than qualitative resistance due to the multiple loci controlling selection pressure on pathogen populations (Parlevliet, 2002; Pilet-Nayel et al., 2017). However a slow erosion of some QTLs has already been demonstrated (Caffier et al., 2014, 2016). 
Acibenzolar-S-methyl (ASM), a functional salicylic acid analog, is one of the most promising PRIs on several plant species (Gozzo and Faoro, 2013). It promotes systemic acquired resistance (SAR) and consequently the induction of various defense responses including pathogenesis-related proteins, leading to the protection of many species against a broad spectrum of pathogens (Romero et al., 2001; Assis et al., 2015; Matsuo et al., 2019; Youssef et al., 2019; Ishiga et al., 2020). On apple, several studies reported significant control of apple scab (Bengtsson et al., 2006, 2009; Marolleau et al., 2017) and fire blight (Brisset et al., 2000; Maxson-Stein et al., 2002; Hassan and Buchenauer, 2007; Abo-Elyousr et al., 2010; Shahini Sough et al., 2010; Dugé de Bernonville et al., 2014; Aćimović et al., 2015; Johnson et al., 2016; Marolleau et al., 2017), as well as the triggering of molecular defense response (Brisset et al., 2000; Ziadi et al., 2001; Maxson-Stein et al., 2002; Dugé de Bernonville et al., 2014; Warneys et al., 2018). Although significant, performance of ASM exhibits variability that remains to be understood for its practical use in the orchard. Among others, the genetic factor is still poorly investigated.

In this paper, we explored the added value of combining intrinsic (genetic) resistance against apple scab and fire blight with induced resistance conferred by ASM using a genetic mapping approach. QTLs composition in a segregating population was compared between ASM-treated and -untreated plants in order to highlight genetic determinants which could explain or interact with ASM performance.

\section{Materials and Methods}

Plant material. All experiments were performed with a F1 population referred as the 'TxF progeny' and previously described in Laloi et al. (2016). The 267 individuals were derived from a controlled cross between TN10-8 and Fiesta, two genotypes partially resistant to apple scab. Fiesta is also partially resistant to fire blight. For each 
experiment, up to ten replicates per individual were grafted and grown in greenhouse under semi-controlled growing conditions $\left(23^{\circ} \mathrm{C}\right.$ day $/ 20^{\circ} \mathrm{C}$ night, humidity $40-80 \%$ and artificial light to complement natural light). Graftwood was collected from a conservatory orchard located at INRAE (Angers, France) and grafted on MM106 apple rootstock. The two parents and two susceptible control cultivars (Golden Delicious and Gala) were also included in each experiment in 10 replicates.

\section{Experimental design, treatment application and phenotypic data collection. For} each experiment, out of the ten, four replicates with active growing shoots per individual and treatment condition were chosen and distributed in each treatment group in randomized blocks in the greenhouse. Two days before inoculation, plants were sprayed with a solution of BION® 50 WG (50\% ASM; Syngenta, Basel, Switzerland) (called ASM treatment) or with reverse osmosis water as control (called the water control). A water dilution of 0.2 g.L-1 for $V$. inaequalis-inoculated plants and 0.4 g.L-1 for E. amylovora-inoculated ones was applied. The commercial advice $\left(0.4 \mathrm{~g} . \mathrm{L}^{-1}\right)$ was reduced for scab to maintain enough phenotypic variability across TxF progeny.

Two V. inaequalis isolates were used: the reference isolate EU-B04 (Origin : Belgium, host : Golden Delicious) previously described in Caffier et al. (2015) and Le Cam et al. (2019) and the isolate 09BCZ014 (Origin : France, host : TN10-8 x Prima progeny (individual E063), referred to as isolate 2557 in Laloi et al. (2016)). Monoconidial suspensions were prepared from diseased dry leaves at a concentration of $2.5 \times 10^{5}$ conidia. $\mathrm{mL}^{-1}$ and, sprayed on grafted trees, incubated thereafter two days at $17^{\circ} \mathrm{C}$ under plastic sheet to maintain a high humidity, according to the conditions described by Caffier et al. (2010). The percentage of leaf surface exhibiting sporulating lesions was scored at 14,21 and 28 days post-inoculation using the ordinal scale (0-7) 
123 described in Calenge et al. (2004). Two experiments were performed with isolate EUB04 (coded Vi-B04_1 et Vi-B04_2) and one with 09BCZ014 (coded Vi-Z14).

The reference strain CFPB1430 of E. amylovora from the French collection of phytopathogenic bacteria (Paulin and Samson, 1973) was used for inoculation. The bacterial suspension was prepared as described in Dugé de Bernonville et al. (2014) at $10^{8}$ colony-forming units (CFU). $\mathrm{mL}^{-1}$. Growing shoots $(>10 \mathrm{~cm})$ were inoculated by cutting the two youngest unrolled leaves with scissors previously soaked in the bacterial suspension. The length of necrosis developing on stem was measured at 7 , 14 and 21 days post-inoculation. The ratio between necrosis length and total shoot length was used as a severity score. Two experiments were performed (coded Ea1430_1 and Ea-1430_2).

Data analysis of phenotypic data. Phenotypic data were analyzed separately for ASM treatment or the water control. The area under the disease-progress curve (AUDPC) was calculated as a quantitative summary of disease severity over time:

$\mathrm{AUDPC}=\sum_{i=0}^{2} \frac{y_{i}+y_{i+1}}{2} x\left(t_{i+1}-t_{i}\right)$

where $y_{i}$ is the disease score at the $i^{\text {th }}$ day of observation and $t_{i}$ the number of day postinoculation at the $\mathrm{i}^{\text {th }}$ observation.

All statistical analyses were performed using R software (Dalgaard, 2010). AUDPC were fitted for environmental trend effects using SpATS package (Rodríguez-Álvarez et al., 2018) which estimates a Best Linear Unbiased Prediction (BLUP) for each individual. Broad-sense heritability of each trait for each treatment was also estimated with the function 'getHeritability' of the same package. 
145 Genotyping data and genetic maps construction. DNA was extracted from fresh young leaf samples using oKtopure ${ }^{\mathrm{TM}}$ LGC Genomics robot and quantified with Hoechst protocol. The TxF progeny was genotyped with the Illumina Infinium 20K SNPs array (Bianco et al., 2014). Genotyping data were analyzed using GenomeStudio® Genotyping Module (V2.0, Illumina Inc., San Diego, California, USA) software with manual correction whenever necessary to improve dataset quality. Markers were filtered according to their parental segregation profile (ABXAA for the female map and $A A x A B$ for the male map; markers in $A B x A B$ were not considered). Then a linkage map was constructed for each parent with JoinMap 4.1 software using the Kosambi mapping function (Van Ooijen, 2006). Map quality was checked by comparison with the apple reference genetic map of Di Pierro et al. (2016) and an updated version of the map (Howard et al., submitted). The software BiomercatorV4.2 (Arcade et al., 2004) was used to curate manually erroneous marker positions. Seventeen microsatellite (SSR) markers located in genomic regions where scab resistance QTLs were expected according to previous publications were added after genotyping of the TxF progeny (Supplementary Table S1).

QTL mapping. In order to compare the contribution of QTLs in resistance and in the interaction between genotypes and ASM, a mapping of QTLs was performed independently in water-control and ASM-treated populations. QTL analyses were conducted using the R/qtl package (Broman et al., 2003). Simple interval mapping (SIM) and composite interval mapping (CIM) were estimated using multiple imputation method and normal distribution model. Cofactors for CIM were determined from the best prediction model simulated with 'stepwise' function. LOD score threshold were determined using 1000 permutations to identify the statistically significant QTLs ( $\alpha=$ 0.05 genome-wide). LOD thresholds were about 5 for both scab and fire blight 
experiments. Suggestive QTLs with LOD score between 3 and 5 were also considered. LOD score, 2-LOD support confidence interval $(\mathrm{Cl})$ and contribution of each QTL to the overall phenotypic variance (individual $R^{2}$ ) were extracted from R/qtl analyses, together with the global QTL contribution (global $\mathrm{R}^{2}$ ). Individual and global $\mathrm{R}^{2}$ were calculated with the 'fitttl' (for fitting a defined multiple-QTL model) function. Interactions between QTLs were studied by variance analysis using the genotyping data of each SNP closest to the peak of each QTL and were detailed by the 'effectplot' function. These results were used to define the model for the calculation of the global $R^{2}$ with 'fitqtl'. To adequately compare QTL effects between treatments by taking into account the overall phenotypic variation in each treatment, relative QTL effect (rEffect) were calculated for each QTL as follows: $r$ Effect $=\frac{1}{\sigma_{B}} \times \frac{|\mathrm{BLUP}(\mathrm{AA})-\mathrm{BLUP}(\mathrm{AB})|}{2}$, where AA and $\mathrm{AB}$ are the allelic versions at the SNP closest to the QTL peak and $\sigma_{B}$ is the standard deviation of BLUP (adjusted for all other significative QTLs effects than the QTL considered) for a given treatment condition. The confidence intervals at $5 \%$ of rEffects were simulated by bootstrapping with 5000 replicates using 'boot' function: when comparing rEffects of a given QTL between the water control and ASM treatment, the overlap of the confidence intervals was interpreted as if the effects were not significantly different. For simplicity, QTL alleles were then considered equivalent to SNP alleles at QTL peaks. Besides, a QTL detected at almost the same genomic position in various experiments were considered and named as the same QTL.

In Vi-B04 experiments, a clear bimodal distribution was observed (see results below). This distribution fitted with the strong effect of the major QTL (simply called qT1 here) detected on LG1 of TN10-8 after inoculation with this isolate (Calenge et al., 2004) or with a mixture of isolates including EU-B04 (Lê Van et al., 2012). For that reason, the TxF progeny was subdivided into two subsets of individuals according to the 
presence/absence of the resistance allele at qT1 predicted by SNP data at the QTL peak. QTL analyses were then conducted on both sub-populations (further called qT1+ and qT1- sub-populations). Conversely, isolate 09BCZ014 was shown to partially overcome the QTL qT1 by Laloi et al. (2016; isolate '2557'). QTL analysis was thus performed on the whole TxF progeny with the latter isolate.

\section{Results}

Phenotypic variability. Only experiments involving the most replicates per individual, Vi-B04_1, Vi-Z14 and Ea-1430_1 are presented here (the two additional experiments Vi-B04_2 and Ea-1430_2 are available as supplementary data).

A significant reduction of AUDPC was observed for both scab and fire blight after ASM treatment compared to the water control (Table 1). For the TxF progeny, AUDPC was reduced by $54 \%$ for Vi-B04_1, 73\% for Vi-Z14 and 50\% for Ea-1430_1. Similar reductions were observed for the two parents and susceptible controls (Figure 1). A large variation was observed among individuals regardless of the conditions, with AUDPC values ranging from 0 to 150 for Vi-B04_1, from 0 to 75 for Vi-Z14 and from 1 to 11 for Ea-1430_1 (Figure 1). A higher coefficient of variation was observed for scab $(C V=0.75-1.27)$ than for fire blight $(C V=0.27-0.34$; Table 1$)$. The distributions were generally unimodal except for the water control in Vi-B04_1 where a clear bimodal distribution was observed (Figure 1A), fitting with the expected effect of QTL qT1 (see Materials and Methods). Broad-sense heritabilities $\left(h^{2}\right)$ were generally high whatever the conditions, ranging from 0.63 for fire blight after ASM treatment to 0.94 for scab after the water control (Table 1). Adjusting the data for spatial effects resulted in a limited increase of heritability from 0.01 to 0.08 units compared to no adjustment (data not shown). Correlation coefficients (Cor) between the water control and ASM 
220 treatment were intermediate to high $(0.6-0.9)$ according to the experiments (Figure 1). The range of AUDPC values observed in ASM-treated individuals increased as

AUDPC values of the corresponding water-treated individuals increased, suggesting interactions between genotypes and treatments especially for the less resistant individuals (Figure 1). AUDPC mean values were lower in Vi-B04_2 and Ea-1430_2 experiments but the variation of AUDPC was similar (Supplementary Table S2 and Supplementary Figure S1). The correlation coefficients between both Vi-B04 experiments were 0.74 for the water control and 0.73 for ASM-treatment, while they were only 0.19 and 0.16 between both Ea_1430 experiments, respectively.

QTL detection for V. inaequalis isolate 'EU-B04'. A total of 6245 SNPs was found polymorphic in the TxF progeny and one or both parents. After discarding 4433 SNPs polymorphic in both parents and redundant, two parental genetic maps of 17 linkage groups were constructed with 853 and 959 SNPs for TN10-8 and Fiesta, respectively. Both parental maps were merged in a single file for further detections of QTLs (Supplementary Table S3).

For the water control condition, a major QTL effect (LOD $\sim 77 ; R^{2}=69.9 \%$ ) was detected on LG1 together with three other significant QTLs on LG T13, F11 and F17 and one suggestive on LG F12 when considering the whole TxF progeny (Supplementary Table S4, Figure 2). The presence of the former QTL (corresponding to qT1) was consistent with the bimodal distribution observed above. In the qT1- subpopulation, four significant QTLs and one suggestive QTL were detected on linkage groups T13, F3, F11, F17 and F12, respectively (Table2, Figure 2). They explained from 3.7 to $29.0 \%$ of phenotypic variation and their relative effect (rEffect) varied from 0.32 (QTL qF12) to 0.66 (QTL qF17), compared to 0.85 for QTL qT1 in the whole TxF progeny (Figure 2). A significant interaction was found between QTLs qF11 and qF17 
245 (Table 3). No AUDPC difference was detectable between both alleles of qF11 when 246 the 'unfavorable' (i.e., susceptible) allele of qF17 (AA) was present (genotypic classes AA:AA and AB:AA with high AUDPC values at 149.6 and 146.2, respectively). With the 'favorable' (i.e., resistant) allele of qF17, the 'favorable' allele of qF11 was on the contrary very efficient with AUDPC values decreasing from 131.3 to 99.5 for the combination of $Q T L$ alleles $A A: A B$, indicating a complementary relationship between 'favorable' alleles of both QTLs. Altogether, QTLs on LG T1, T13, F11, F12 and F17 explained $81.9 \%$ of phenotypic variation in the whole progeny, whereas the five QTLs including the QTL interaction explained $65.1 \%$ of phenotypic variation in the qT1- subpopulation (Table 1). For ASM-treatment condition, QTL qT1 still exhibited a strong effect (LOD 46; $R^{2}=60 \%$ ) in the whole TxF progeny (Supplementary Table S4, Figure 2) together with QTLs $\mathrm{qF} 17$ and $\mathrm{qF} 11$ as a suggestive QTL (Supplementary Table S4). All three explained $70.2 \%$ of the phenotypic variation. In the qT1- subpopulation, only three out of the five QTLs detected in the water-control condition were detected (Table 2). QTLs qT13 and qF3 completely disappeared after ASM treatment with a LOD score lower than 0.2 at the SNP near to the peak of the same QTL detected in the water control and a non-significant effect for qF3 (Figure 2). The three other QTLs were detected at roughly the same positions on linkage groups as with the water control and the significant interaction between $\mathrm{qF} 11$ and $\mathrm{qF} 17$ was also found with the same pattern as above (Table 3). Their relative effects were not significantly different from the water control and were thus not significantly modulated by ASM treatment, despite much stronger LOD score and $\mathrm{R}^{2}$ for $\mathrm{qF} 17$ (21.2 and $39.9 \%$ with $\mathrm{ASM}$ treatment compared to 12.4 and $29.0 \%$ with the water control) and lower LOD score and $\mathrm{R}^{2}$ for $\mathrm{qF} 11$ (7.6 and $10.7 \%$ compared to 10.7 and $18.1 \%$, respectively) (Table 2, Figure 2). 
270 For experiment Vi-B04_2, the same QTLs were detected despite at lower LOD scores than in the first experimentation (Supplementary Table S5). In the whole TxF progeny, qT1 was still detected as the strongest QTL for both treatment conditions (LOD 35; $\mathrm{R}^{2} \sim 40-48 \%$ ) together with $\mathrm{qF} 11$ and $\mathrm{qF} 12$ as suggestive QTL (water control) and $\mathrm{qF} 17$ (both conditions) and still a significant interaction between $\mathrm{qF} 11$ and $\mathrm{qF} 17$ (Supplementary Table S6, water control). In the qT1- sub-population, qF17 was the single significant QTL detected, while $\mathrm{qT} 13$, $\mathrm{qF} 3, \mathrm{qF} 11$ and $\mathrm{qF} 12$ were detected as suggestive QTLs with mostly similar $\mathrm{R}^{2}$ compared to the Vi-B04_1 experiment. Three significant interactions between QTLs were detected, two of them involving qT13 with qF11 and qF17 respectively (Supplementary Table S6). In this experiment, ASM treatment did not significantly modulate the QTL effect on any of the QTLs detected (Supplementary Figure S2).

QTL detection for $V$. inaequalis isolate '09BCZ14'. For the water control condition, all the QTLs detected in Vi-B04_1 were also detected in Vi-Z14, except on LG F12, and a new suggestive QTL was detected on LG T10. The phenotypic variation explained by these QTLs ranged from 3.5 to $10.7 \%$ and the relative effects from 0.25 (QTL qT10) to 0.42 (QTLs qT13 and qF17) (Table 2, Figure 2). Interaction between QTLs $\mathrm{qF} 11$ and $\mathrm{qF} 17$ was still significant whereas new interactions were found significant between qT1 and qF3, between qT13 and qF3 and between qT10 and qF11 (Table 3). Altogether, these QTLs and interactions explained $47.5 \%$ of the phenotypic variation (Table 1). For ASM-treatment condition, three out of the six QTLs identified in the water control were still detected but only as suggestive QTLs (qT13, qF11, qF17; Table 2). Altogether, they explained only $15.0 \%$ of the phenotypic variation without any interactions. The relative effects of these QTLs were not significantly different when 
compared with the water control (Figure 2). Conversely, the relative effect of qT1 was significantly lower for ASM treatment than for the water control (Figure 2).

QTL mapping for fire blight resistance. For the water control condition, four QTLs (two significant and two suggestive) were detected on LG T3, T5, F7 and F15 explaining from 3.1 to $20.1 \%$ of total phenotypic variation (Table 2, Figure 3). Altogether, these QTLs explained $35.0 \%$ of the phenotypic variation. The same QTLs except LG F15 were found for ASM-treatment condition, together with a new significant variation (33.1\% altogether). On LG T5, the peak of the QTLs was offset by $\sim 20 \mathrm{cM}$ between the water control and ASM treatment, which suggests two different QTLs. The relative effects of these QTLs were not significantly different when compared with the water control (Figure 3). No significant interaction could be identified between the QTLs in both conditions.

In the Ea-1430_2 experiment for water-control condition, three QTLs previously identified were maintained (qT3, qT5, qF15), two new QTLs were detected (qT15, qF5) and one was no longer detected (qF7) (Supplementary Table S5). Surprisingly, qF7 was the QTL with the strongest effect in the first experiment; only a weak peak was detected here with a LOD of 1.8. For ASM treatment condition, three new QTLs qT1, qT7 and qF1 were identified while three others disappeared (qT3, qT15, qF15). The QTL interactions in the two conditions are totally different (Supplementary Table S6). Among the nine QTLs identified, qT3 and $\mathrm{qF15}$ relative effect were significantly modulated by ASM (Supplementary Figure S3).

\section{Discussion}

317 A first result of our study has been to confirm already known scab and fire blight resistance QTLs and to detect new ones under the water control condition. For scab 
resistance, QTLs located on LG1 of TN10-8 (qT1) and on LG11 and LG17 of Fiesta (qF11 and qF17, respectively) were previously detected and confirmed in various studies (Durel et al., 2003; Liebhard et al., 2003; Calenge et al., 2004; Soufflet-Freslon et al., 2008; Lê Van et al., 2012). The added value of the present study is the refinement of their genetic position with reduced confidence intervals compared to previous studies. As stated above, qT1 is precisely colocalized with the Rvi6 (Vf) gene at position $43.03 \mathrm{cM}$ of the genetic map corresponding to the $\mathrm{CH}-\mathrm{Vf} 1 \mathrm{SSR}$ marker, tightly associated to that R-gene (Vinatzer et al., 2004). qT1 is thus a potential allele or paralog of Rvi6 and can thus be postulated as an extracellular leucine-rich repeat receptor-like gene (Belfanti et al., 2004; Calenge et al., 2004). Another key aspect is the confirmation of the strong complementary (synergistic) interaction between qF11 and qF17 as already highlighted by Caffier et al. (2014). Such an interaction can be interpreted as the complementary action of two genes successively involved in a metabolic pathway (McMullen et al., 1998). The dependency of the qF11 allelic contrast upon the unfavorable or favorable allele of $\mathrm{qF} 17$ could be tentatively interpreted as an upstream position of the gene underlying qF17 and a downstream position of the gene underlying $\mathrm{qF} 11$. Thus, $\mathrm{qF} 11$ and $\mathrm{qF} 17$ could rather be involved in a signaling or defense pathway, unlike qT1 more probably involved in pathogen effector or PAMP recognition. Although reduced, the confidence intervals of these QTLs were still too wide to search for sufficiently plausible candidate genes. An attempt was made for qF17 and yielded over 160 positional candidates (data not shown). New scab resistance QTLs were detected on LGs 10 and 13 of TN10-8 and LGs 3 and 12 of Fiesta. The most significant were $\mathrm{qT} 13$ and $\mathrm{qF} 3$ detected at genomic positions not yet identified in other scab resistance studies. They will therefore be considered as a priority for further marker-assisted breeding. 
344 For fire blight resistance, the QTL qF7 was consistently detected on LG7 of Fiesta in the first experiment as already published (Calenge et al., 2005; Khan et al., 2007). The refinement of its genetic position was allowed with reduced confidence intervals compared to previous studies. This QTL was shown to interact with two other ones on LG8 and LG13 (van de Weg et al., 2018), but these genomic regions were not detected in our study. Implication in a metabolic pathway could nevertheless be postulated for qF7 due to such interactions. We also identified resistance QTLs on LGs 3, 5 and 15 which may coincide with those published by Calenge et al. (2005), Durel et al. (2009) and Le Roux et al. (2010) respectively, despite their genomic position was not very accurate. In our second experiment, qF7 was no more detected which calls into question the relevance of this experiment, especially in view of the low AUDPC and heritability values obtained and the weak correlation between both Ea-1430 experiments. This second experiment was performed very early in the season (early February) at an unusual time for fire blight experiment which could explain this surprising result.

In the present study, we propose for the first time a QTL mapping approach to search for genetic factors influenced by a PRI. A few studies highlighted the influence of genotypes on the effectiveness of PRIs but without any link with intrinsic genetic resistance of varieties (Vallad and Goodman, 2004; Sharma et al., 2010; Maisonneuve et al., 2013). Pawlowski et al. (2016) underlined the specific interaction between the genetic and PRI-induced resistance but did not characterize the genetic resistance factors. A mapping approach has the advantage of exploring in detail the putative modulation of genetic resistance factors by PRIs. In our study, the results show that genetic resistance controlled by QTLs is only slightly or rarely affected by ASM treatment. Out of the seven scab resistance QTLs detected, only two QTLs (qF3 for 
Vi-B04_1, and qT1 for Vi-Z14) almost disappeared after treatment with ASM. We also

370 detected two fire blight resistance QTLs (qT3, qF15) which effects significantly

371 decreased after ASM treatment in the second Ea-1430 experiment, but the experimental conditions were questionable. Despite a large mapping population, the confidence intervals surrounding relative effects of QTLs were large and therefore precluded the detection of low modulation of QTL effects by ASM. More individuals and replicates per individual would have been necessary to detect such modulations. Furthermore, no QTL specific to the ASM treatment condition was detected: all QTLs detected with ASM were already identified as resistance QTLs under the water control. The general trend was either a maintenance or a reduction in the relative effect of QTLs. Some of them fully disappeared (significantly) but this observation was hard to repeat for both diseases. To some extent, this QTL effect disappearance could also be explained by a scale effect. Indeed, the application of ASM strongly reduces the global variability in disease severity and the weakest QTLs under the water control can become insignificant under ASM treatment due to a consequent lack of statistical power. However, a general trend of maintenance or small reduction of most QTLs is surprising: considering the overall effectiveness of ASM on reducing disease symptoms and the interactions observed between less resistant genotypes and treatment, it would have been expected to found more interactions between pathways leading to this resistance.

To go further, according to the diverse nature of the QTLs present in our population, we expected to observe some QTLs responding to ASM and others remaining unchanged. ASM is known to act on salicylic acid signaling pathway. In tobacco, it is perceived by the SABP2 protein (Salicylic acid-binding protein 2) which transforms it into acibenzolar which then interacts with NPR1 to activate the transcription of a set of 
genes in the SAR pathway (Tripathi et al., 2010; Warneys et al., 2018; De Jong et al., 2019; Ishiga et al., 2020; Li et al., 2020). If we consider the three stages of resistance build-up, namely recognition, signaling and defense, we could postulate that QTLs involved in signaling and defense could be more affected by ASM than QTLs involved in effectors or PAMPs recognition. However, the qT1 previously described as most probably involved in pathogen recognition disappeared with 09BCZ014 isolate but not with EU-B04, whereas the QTLs $\mathrm{qF} 11$, $\mathrm{qF} 17$ and $\mathrm{qF7}$, potentially rather involved in signaling or defense pathways were not significantly affected by ASM. Various hypotheses can be formulated for interpreting our results. In Arabidopsis, Tsuda et al. (2009) showed that each of the salicylic acid (SA), jasmonic acid (JA) and ethylene (ET) signaling sectors can positively contribute to immunity against both biotrophic and necrotrophic pathogens. The authors schematized various situations of compensation or synergy between different sectors of a complex signaling network where the effector or PAMP recognition (input) can generate equivalent restriction of pathogen growth (output) while mobilizing very different sectors interacting or not. In our situation, ASM treatment would reinforce one of the signaling sectors with possible consequences on other sectors given SA versus JA/ET compensation, while resistance QTLs positioned at various locations of the network would impact the flow along some of these pathways. Some of the detected QTLs could therefore be located on metabolic pathways independent of the SA pathway while others could be implied in the SA pathway and thus be affected by the strong initial supply of ASM. In-depth exploration of the metabolic mechanisms involved in genotypes carrying or not resistance QTL alleles, with or without ASM treatment, is needed to precise the interactions between pathways. 
418 Our study revealed that the intrinsic resistance controlled by QTLs and the resistance 419 induced by ASM have a complementary effect for the control of apple scab and fire 420 blight. In our study, the average effectiveness of ASM in reducing the disease ranged from 50\% for Ea-1430_1 to 78\% for V1-B04_2. Under the water control, the individuals cumulating favorable alleles at all detected QTLs exhibited a disease reduction of $91 \%$ for Vi-B04_1 and 98\% for Vi-Z14 compared to individuals carrying only unfavorable QTL alleles for scab, and $78 \%$ for fire blight. When intrinsic and ASM-induced resistance was combined, the disease reduction was close to $100 \%$ for scab and $85 \%$ for fire blight. These results confirm that there is no incompatibility between intrinsic and ASM-induced resistance for apple as reported for cucumber (da Rocha and Hammerschmidt, 2005). The present results were obtained under controlled conditions but arguments suggest that the same trends could be observed in orchards. On the one hand, Caffier et al. $(2014,2016)$ showed that quantitative resistance related to QTLs qT1, qF11 and qF17 significantly reduced scab severity in orchards. On the other hand, Marolleau et al. (2017) confirmed that ASM could be integrated into orchard protection practices to control apple scab. Combining both types of resistance in the orchard should allow a better control of apple scab and similarly for fire blight.

In addition to improve protection effectiveness, the interest in combining intrinsic and PRI-induced resistance could rely in a cross-protection of both types of resistance through a diversification of selection pressures on pathogen populations which would reduce or slow down their adaptation (Lê Van et al., 2013; Caffier et al., 2014). The use of ASM in combination with genotypes cumulating several QTLs involved in different defense pathways could be a promising sustainable protection for the control of apple scab and fire blight. A thorough analysis of the mechanisms activated by this 
resistance will confirm these hypotheses and all of these results must be confirmed in the orchards for possible integration into the protection practices.

\section{Acknowledgements}

The authors greatly thank the PHENOTIC platform, especially M. Boucourt, C. Cattanéo, C. Colas and R. Gardet, for carefully taking care of the plant material in the greenhouse. They thank the Horticole Experimental Unit (UE Horti) for maintaining the trees over many years in a conservatory orchard belonging to the BRC RosePom. X.

Cazenave, E. Chevreau, R. Cournol, A. Degrave, C. Denancé, N. Dousset, C. Heintz, A. Juillard, L. Lejus, J. Malabarba, K. Menacer, H. Muranty, A. Petiteau, C. Pubert, P. Robert, E. Vergne helped in preparing the experiments and in scoring apple scab and fire blight disease in the greenhouse: they are all warmly thanked. The genetic map was carefully checked thanks to an updated version of the reference genetic map kindly furnished by N. Howard. They thank E. Millet, D. Lopez-Arias and S. Adamowicz for sharing $\mathrm{R}$ scripts for analysis of field trial experiments, QTLs detection and bootstrapping, respectively.

\section{Literature Cited}

Abo-Elyousr, A.M.K., Sallam, M.A.A., Hassan, M.H.A. and Zeller, W. 2010. Effect of Acibenzolar-S-methyl and Rahnella aquatilis ( Ra39) on chitinase and $\beta-1,3-$ glucanase activities and disease resistance of apple plants. Plant Pathol. J. 26: 63-69.

Aćimović, S.G., Zeng, Q., McGhee, G.C., Sundin, G.W. and Wise, J.C. 2015. Control of fire blight (Erwinia amylovora) on apple trees with trunk-injected plant resistance inducers and antibiotics and assessment of induction of pathogenesis-related protein genes. Frontiers in Plant Science 6: 1-10.

Arcade, A., Labourdette, A., Falque, M., Mangin, B., Chardon, F., Charcosset, A. and Joets, J. 2004. BioMercator: integrating genetic maps and QTL towards discovery of candidate genes. Bioinformatics 20: 2324-2326.

Assis, F.A., Moraes, J.C., Assis, G.A. and Parolin, F.J.T. 2015. Induction of caterpillar resistance in sunflower using silicon and acibenzolar-S-methyl. J. Agr. Sci. Tech. 17: $543-550$.

Bektas, Y. and Eulgem, T. 2015. Synthetic plant defense elicitors. Frontiers in Plant 
Science 5: 1-9.

Belfanti, E., Silfverberg-Dilworth, E., Tartarini, S., Patocchi, A., Barbieri, M., Zhu, J., Vinatzer, B.A., Gianfranceschi, L., Gessler, C. and Sansavini, S. 2004. The HcrVf2 gene from a wild apple confers scab resistance to a transgenic cultivated variety. Proceedings of the National Academy of Sciences of the United States of America 101: 886-890.

Bengtsson, M., Lyngs Jørgensen, H.J., Pham, A., Wulff, E. and Hockenhull, J. 2006. Screening of organically based fungicides for apple scab (Venturia inaequalis) control and a histopathological study of the mode of action of a resistance inducer. Pome Fruit Diseases IOBC/wprs Bull 29: 123-127.

Bengtsson, M., Wulff, E., Lyngs Jørgensen, H.J., Pham, A., Lübeck, M. and Hockenhull, J. 2009. Comparative studies on the effects of a yucca extract and acibenzolar-S-methyl (ASM) on inhibition of Venturia inaequalis in apple leaves. European Journal of Plant Pathology 124: 187-198.

Bianco, L., Cestaro, A., Sargent, D.J., Banchi, E., Derdak, S., Di Guardo, M., Salvi, S., Jansen, J., Viola, R., Gut, I., Laurens, F., Chagné, D., Velasco, R., van de Weg, E. and Troggio, M. 2014. Development and validation of a $20 \mathrm{~K}$ single nucleotide polymorphism (SNP) whole genome genotyping array for Apple (Malus $\times$ domestica Borkh). PLoS ONE 9: e110377.

Boudichevskaia, A., Flachowsky, H. and Dunemann, F. 2009. Identification and molecular analysis of candidate genes homologous to HcrVf genes for scab resistance in apple. Plant Breeding 128: 84-91.

Brisset, M.-N., Cesbron, S., Thomson, S. V. and Paulin, J. 2000. Acibenzolar-S-methyl induces the accumulation of defense-related enzymes in apple and protects from fire blight. European Journal ofPlant Pathology 106: 529-536.

Broggini, G.A.L., Galli, P., Parravicini, G., Gianfranceschi, L., Gessler, C. and Patocchi, A. 2009. HcrVf paralogs are present on linkage groups 1 and 6 of Malus. Genome 52: 129-138.

Broman, K.W., Wu, H., Sen, Ś. and Churchill, G.A. 2003. R/qtl: QTL mapping in experimental crosses. Bioinformatics 19: 889-890.

Burketova, L., Trda, L., Ott, P.G. and Valentova, O. 2015. Bio-based resistance inducers for sustainable plant protection against pathogens. Biotechnology Advances 33: 994-1004.

Caffier, V., Le Cam, B., Al Rifaï, M., Bellanger, M.-N., Comby, M., Denancé, C., Didelot, F., Expert, P., Kerdraon, T., Lemarquand, A., Ravon, E. and Durel, C.-E. 2016. Slow erosion of a quantitative apple resistance to Venturia inaequalis based on an isolate-specific quantitative trait locus. Infection, Genetics and Evolution 44: $541-548$.

Caffier, V., Didelot, F., Pumo, B., Causeur, D., Durel, C.E. and Parisi, L. 2010. Aggressiveness of eight Venturia inaequalis isolates virulent or avirulent to the major resistance gene Rvi6 on a non-Rvi6 apple cultivar. Plant Pathology 59: 1072-1080.

Caffier, V., Lasserre-Zuber, P., Giraud, M., Lascostes, M., Stievenard, R., 
Lemarquand, A., van de Weg, E., Expert, P., Denancé, C., Didelot, F., Le Cam, B. and Durel, C.-E. 2014. Erosion of quantitative host resistance in the apple $\times$ Venturia inaequalis pathosystem. Infection, Genetics and Evolution 27: 481-489.

Caffier, V., Patocchi, A., Expert, P., Bellanger, M.-N., Durel, C.-E., Hilber-Bodmer, M., Broggini, G.A.L., Groenwold, R. and Bus, V.G.M. 2015. Virulence characterization of Venturia inaequalis reference isolates on the differential set of Malus hosts. Plant Disease 99: 370-375.

Calenge, F., Drouet, D., Denancé, C., van de Weg, W.E., Brisset, M.-N., Paulin, J.-P. and Durel, C.-E. 2005. Identification of a major QTL together with several minor additive or epistatic QTLs for resistance to fire blight in apple in two related progenies. Theoretical and Applied Genetics 111: 128-135.

Calenge, F., Faure, A., Goerre, M., Gebhardt, C., van de Weg, W.E., Parisi, L. and Durel, C.-E. 2004. Quantitative trait loci (QTL) analysis reveals both broadspectrum and isolate-specific QTL for scab resistance in an apple progeny challenged with eight isolates of Venturia inaequalis. Phytopathology 94(4): 370379.

Howard, N.P., Troggio, M., Durel, C.-E., Muranty, H., Denancé, C., Bianco, L.; Tillman, J. and van de Weg, E. 2020. Integration of Infinium and Axiom SNP array data in the outcrossing species Malus $\times$ domestica and causes for seemingly incompatible calls. BioRxiv 2020.09.01.276758.

Le Cam, B., Sargent, D., Gouzy, J., Amselem, J., Bellanger, M.-N., Bouchez, O., Brown, S., Caffier, V., De Gracia, M., Debuchy, R., Duvaux, L., Payen, T., Sannier, M., Shiller, J., Collemare, J. and Lemaire, C. 2019. Population genome sequencing of the scab fungal species Venturia inaequalis, Venturia pirina, Venturia aucupariae and Venturia asperata. G3: Genes, Genomes, Genetics 9: 2405-2414.

Celton, J.M., Tustin, D.S., Chagné, D. and Gardiner, S.E. 2009. Construction of a dense genetic linkage map for apple rootstocks using SSRs developed from Malus ESTs and Pyrus genomic sequences. Tree Genetics and Genomes 5: 93-107.

Costa, F., van de Weg, W.E., Stella, S., Dondini, L., Pratesi, D., Musacchi, S. and Sansavini, S. 2008. Map position and functional allelic diversity of $M d-E x p 7$, a new putative expansin gene associated with fruit softening in apple (Malus $x$ domestica Borkh.) and pear (Pyrus communis). Tree Genetics and Genomes 4: 575-586.

Dalgaard, P. 2010. R development core team (2010): R: A language and environment for statistical computing. Computer p, http://www.r-project.org/.

Dugé de Bernonville, T., Marolleau, B., Staub, J., Gaucher, M. and Brisset, M.-N. 2014. Using molecular tools to decipher the complex world of plant resistance inducers: an apple case study. Journal of Agricultural and Food Chemistry 62: 1140311411.

Durel, C.-E., Denancé, C. and Brisset, M.-N. 2009. Two distinct major QTL for resistance to fire blight co-localize on linkage group 12 in apple genotypes 'Evereste' and Malus floribunda clone. NRC Research Press 147: 139-147.

Durel, C.E., Parisi, L., Laurens, F., van de Weg, W.E., Liebhard, R. and Jourjon, M.F. 2003. Genetic dissection of partial resistance to race 6 of Venturia inaequalis in 
apple. Genome 46: 224-234.

Emeriewen, O.F., Wöhner, T., Flachowsky, H. and Peil, A. 2019. Malus hosts-Erwinia amylovora interactions: strain pathogenicity and resistance mechanisms. Frontiers in Plant Science 10: 1-7.

Gozzo, F. and Faoro, F. 2013. Systemic acquired resistance (50 years after discovery): moving from the lab to the field. Journal of Agricultural and Food Chemistry 61: 12473-12491.

Hassan, M.A.E. and Buchenauer, H. 2007. Induction of resistance to fire blight in apple by acibenzolar-S-methyl and DL-3-aminobutyric acid. Journal of Plant Diseases and Protection 114: 151-158.

Hokanson, S.C., Szewc-McFadden, A.K., Lamboy, W.F. and McFerson, J.R. 1998. Microsatellite (SSR) markers reveal genetic identities, genetic diversity and relationships in a Malus $x$ domestica borkh. core subset collection. Theoretical and Applied Genetics 97: 671-683.

Ishiga, T., lida, Y., Sakata, N., Ugajin, T., Hirata, T., Taniguchi, S., Hayashi, K. and Ishiga, Y. 2020. Acibenzolar-S-methyl activates stomatal-based defense against Pseudomonas cannabina pv. alisalensis in cabbage. Journal of General Plant Pathology 86: 48-54.

Johnson, K.B., Smith, T.J., Temple, T.N., Gutierrez, E., Elkins, R.B. and Castagnoli, S.P. 2016. Integration of acibenzolar-S-methyl with antibiotics for protection of pear and apple from fire blight caused by Erwinia amylovora. Crop Protection 88: 149-154.

De Jong, H., Reglinski, T., Elmer, P.A.G., Wurms, K., Vanneste, J.L., Guo, L.F. and Alavi, M. 2019. Integrated use of Aureobasidium pullulans strain CG163 and acibenzolar-S-methyl for management of bacterial canker in kiwifruit. Plants 8: 287.

Khajuria, Y.P., Kaul, S., Wani, A.A. and Dhar, M.K. 2018. Genetics of resistance in apple against Venturia inaequalis (Wint.) Cke. Tree Genetics \& Genomes 14: 16.

Khan, M.A., Durel, C.E., Duffy, B., Drouet, D., Kellerhals, M., Gessler, C. and Patocchi, A. 2007. Development of molecular markers linked to the "Fiesta" linkage group 7 major QTL for fire blight resistance and their application for marker-assisted selection. Genome 50: 568-577.

Laloi, G., Vergne, E., Durel, C.E., Le Cam, B. and Caffier, V. 2016. Efficiency of pyramiding of three quantitative resistance loci to apple scab. Plant Pathology 66: 412-422.

Lê Van, A., Caffier, V., Lasserre-Zuber, P., Chauveau, A., Brunel, D., Le Cam, B. and Durel, C.-E. 2013. Differential selection pressures exerted by host resistance quantitative trait loci on a pathogen population: a case study in an apple $\times$ Venturia inaequalis pathosystem. New Phytologist 197: 899-908.

Lê Van, A., Gladieux, P., Lemaire, C., Cornille, A., Giraud, T., Durel, C., Caffier, V. and Le Cam, B. 2012. Evolution of pathogenicity traits in the apple scab fungal pathogen in response to the domestication of its host. Evolutionary Applications 7: 694-704. 
Li, C., Wei, M., Ge, Y., Zhao, J., Chen, Y., Hou, J., Cheng, Y., Chen, J. and Li, J. 2020. The role of glucose-6-phosphate dehydrogenase in reactive oxygen species metabolism in apple exocarp induced by acibenzolar-S-methyl. Food Chemistry 308: 125663.

Liebhard, R., Gianfranceschi, L., Koller, B., Ryder, C.D., Tarchini, R., van de Weg, E. and Gessler, C. 2002. Development and characterisation of 140 new microsatellites in apple (Malus $x$ domestica Borkh.). Molecular Breeding 10: 217241.

Liebhard, R., Koller, B., Patocchi, A., Kellerhals, M., Pfammatter, W., Jermini, M. and Gessler, C. 2003. Mapping quantitative field resistance against apple scab in a "Fiesta" x "Discovery" progeny. Phytopathology 93: 493-501.

MacHardy, W.E. 1996. Apple scab biology, epidemiology and management. APS Press, St. Paul, Minnesota, USA.

Maisonneuve, B., Allen-aubouard, C. and Pitrat, M. 2013. Effect of plant genotype on the efficacy of stimulators of plant defences in two horticultural pathosystems. IOBC-WPRE Bulletin 89: 327-331.

Malnoy, M., Martens, S., Norelli, J.L., Barny, M.-A., Sundin, G.W., Smits, T.H.M. and Duffy, B. 2012. Fire Blight: applied genomic insights of the pathogen and host. Annual Review of Phytopathology 50: 475-494.

Marolleau, B., Gaucher, M., Heintz, C., Degrave, A., Warneys, R., Orain, G., Lemarquand, A. and Brisset, M. 2017. When a plant resistance inducer leaves the lab for the field: integrating ASM into routine apple protection practices. Frontiers in Plant Science 8: 1-11.

Matsuo, Y., Novianti, F., Takehara, M., Fukuhara, T., Arie, T. and Komatsu, K. 2019. Acibenzolar-S-methyl restricts infection of Nicotiana benthamiana by Plantago Asiatica mosaic virus at two distinct stages. Molecular Plant-Microbe Interactions 32: 1475-1486.

Maxson-Stein, K., He, S., Hammerschmidt, R. and Jones, A.L. 2002. Effect of treating apple trees with acibenzolar-S-methyl on fire blight and expression of pathogenesis-related protein genes. Plant Disease 86: 785-790.

McDonald, B.A. and Linde, C. 2002. Pathogen Population Genetics, Evolutionary potential, and durable resistance. Annual Review of Phytopathology 40: 349-379.

McMullen, M.D., Byrne, P.F., Snook, M.E., Wiseman, B.R., Lee, E.A., Widstrom, N.W. and Coe, E.H. 1998. Quantitative trait loci and metabolic pathways. Proceedings of the National Academy of Sciences of the United States of America 95: 19962000.

Oliveira, M.D.M., Varanda, C.M.R. and Félix, M.R.F. 2016. Induced resistance during the interaction pathogen $x$ plant and the use of resistance inducers. Phytochemistry Letters 15: 152-158.

Van Ooijen, J. 2006. JoinMap® 4, software for the calculation of genetic linkage maps in experimental populations. Wageningen, the Netherlands: Kyazma BV.

Oostendorp, M., Kunz, W., Dietrich, B. and Staub, T. 2001. Induced disease resistance in plants by chemicals. European Journal of Plant Pathology 107: 19-28. 
Pal, K.K. and McSpadden Gardener, B. 2006. Biological control of plant pathogens. The Plant Health Instructor 1-25.

Parisi, L. 1993. A new race of Venturia inaequalis virulent to apples with resistance due to the Vf gene. Phytopathology 83: 533.

Parlevliet, J.E. 2002. Durability of resistance against fungal, bacterial and viral pathogens, present situation. Euphytica 124: 147-156.

Patocchi, A., Wehrli, A., Dubuis, P.-H., Auwerkerken, A., Leida, C., Cipriani, G., Passey, T., Staples, M., Didelot, F., Philion, V., Peil, A., Laszakovits, H., Rühmer, T., Boeck, K., Baniulis, D., Strasser, K., Vávra, R., Guerra, W., Masny, S., Ruess, F., Le Berre, F., Nybom, H., Tartarini, S., Spornberger, A., Pikunova, A., Bus, V.G.M. 2020. Ten years of vinquest: first insight for breeding new apple cultivars with durable apple scab resistance. Plant Disease 104: 2074 - 2081

Paulin, J.P. and Samson, R. 1973. Fire blight in France. II. Characters of the strains of Erwinia amylovora (Burril) Winslow et al., 1920, isolated from a Franco-Belgian focus. Ann. Phytopathol. 5: 389-397.

Pawlowski, M.L., Bowen, C.R., Hill, C.B. and Hartman, G.L. 2016. Responses of soybean genotypes to pathogen infection after the application of elicitors. Crop Protection 87: 78-84.

Peil, A., Emeriewen, O.F., Khan, A., Kostick, S. and Malnoy, M. 2020. Status of fire blight resistance breeding in Malus. Journal of Plant Pathology.

Di Pierro, E.A., Gianfranceschi, L., Di Guardo, M., Koehorst-van Putten, H.J., Kruisselbrink, J.W., Longhi, S., Troggio, M., Bianco, L., Muranty, H., Pagliarani, G., Tartarini, S., Letschka, T., Lozano Luis, L., Garkava-Gustavsson, L., Micheletti, D., Bink, M.C., Voorrips, R.E., Aziz, E., Velasco, R., Laurens, F. and van de Weg, W.E. 2016. A high-density, multi-parental SNP genetic map on apple validates a new mapping approach for outcrossing species. Horticulture Research 3: 16057.

Pilet-Nayel, M.-L., Moury, B., Caffier, V., Montarry, J., Kerlan, M.-C., Fournet, S., Durel, C.-E. and Delourme, R. 2017. Quantitative resistance to plant pathogens in pyramiding strategies for durable crop protection. Frontiers in Plant Science 8: 19.

da Rocha, A.B. and Hammerschmidt, R. 2005. History and perspectives on the use of disease resistance inducers in horticultural crops. HortTechnology 15: 518-529.

Rodríguez-Álvarez, M.X., Boer, M.P., van Eeuwijk, F.A. and Eilers, P.H.C. 2018. Correcting for spatial heterogeneity in plant breeding experiments with P-splines. Spatial Statistics 23: 52-71.

Romero, A.M., Kousik, C.S. and Ritchie, D.F. 2001. Resistance to bacterial spot in bell pepper induced by acibenzolar-S-methyl. Plant Disease 77: 189-194.

Le Roux, P.M.F., Khan, M.A., Broggini, G.A.L., Duffy, B., Gessler, C. and Patocchi, A. 2010. Mapping of quantitative trait loci for fire blight resistance in the apple cultivars "Florina" and "Nova Easygro." Genome 53: 710-722.

Shahini Sough, F., Keshavarzi, M., Hassanzade, N., Hashemi, M., Abdollahi, H. and Tawosi, M. 2010. In vitro evaluation of acibenzolar-S-methyl on inhibition of fire 
Sharma, K., Butz, A.F. and Finckh, M.R. 2010. Effects of host and pathogen genotypes on inducibility of resistance in tomato (Solanum lycopersicum) to Phytophthora infestans. Plant Pathology 59: 1062-1071.

Silfverberg-Dilworth, E., Matasci, C.L., van de Weg, W.E., van Kaauwen, M.P.W., Walser, M., Kodde, L.P., Soglio, V., Gianfranceschi, L., Durel, C.E., Costa, F., Yamamoto, T., Koller, B., Gessler, C. and Patocchi, A. 2006. Microsatellite markers spanning the apple (Malus $x$ domestica Borkh.) genome. Tree Genetics and Genomes 2: 202-224.

Soriano, J.M., Madduri, M., Schaart, J.G., van der Burgh, A., van Kaauwen, M.P.W., Tomic, L., Groenwold, R., Velasco, R., van de Weg, E. and Schouten, H.J. 2014. Fine mapping of the gene Rvi18 (V25) for broad-spectrum resistance to apple scab, and development of a linked SSR marker suitable for marker-assisted breeding. Molecular Breeding 34: 2021-2032.

Soufflet-Freslon, V., Gianfranceschi, L., Patocchi, A. and Durel, C.-E. 2008. Inheritance studies of apple scab resistance and identification of Rvi14, a new major gene that acts together with other broad-spectrum QTL. Genome 51: 657667.

Tripathi, D., Jiang, Y. and Kumar, D. 2010. SABP2, a methyl salicylate esterase is required for the systemic acquired resistance induced by acibenzolar-S-methyl in plants. FEBS Letters 584: 3458-3463.

Tsuda, K., Sato, M., Stoddard, T., Glazebrook, J. and Katagiri, F. 2009. Network properties of robust immunity in plants. PLoS Genetics 5: e1000772.

Vallad, G.E. and Goodman, R.M. 2004. Review \& interpretation in conventional agriculture. Crop Sci. 44: 1920-1934.

Vinatzer, B.A., Patocchi, A., Tartarini, S., Gianfranceschi, L., Sansavini, S. and Gessler, C. 2004. Isolation of two microsatellite markers from BAC clones of the $V f$ scab resistance region and molecular characterization of scab-resistant accessions in Malus germplasm. Plant Breeding 123: 321-326.

Walters, D.R., Ratsep, J. and Havis, N.D. 2013. Controlling crop diseases using induced resistance: challenges for the future. Journal of Experimental Botany 64: 1263-1280.

Warneys, R., Gaucher, M., Robert, P., Aligon, S., Anton, S., Aubourg, S., Barthes, N., Braud, F., Cournol, R., Gadenne, C., Heintz, C., Brisset, M. and Degrave, A. 2018. Acibenzolar-S-methyl reprograms apple transcriptome toward resistance to rosy apple aphid. Frontiers in Plant Science 9: 1-16.

van de Weg, E., Di Guardo, M., Jänsch, M., Socquet-Juglard, D., Costa, F., Baumgartner, I., Broggini, G.A.L., Kellerhals, M., Troggio, M., Laurens, F., Durel, C.E. and Patocchi, A. 2018. Epistatic fire blight resistance QTL alleles in the apple cultivar 'Enterprise' and selection X-6398 discovered and characterized through pedigree-informed analysis. Molecular Breeding 38: 5.

Wiesel, L., Newton, A.C., Elliott, I., Booty, D., Gilroy, E.M., Birch, P.R.J. and Hein, I. 2014. Molecular effects of resistance elicitors from biological origin and their 
potential for crop protection. Frontiers in Plant Science 5: 1-13.

Wöhner, T.W., Flachowsky, H., Richter, K., Garcia-Libreros, T., Trognitz, F., Hanke, M. V. and Peil, A. 2014. QTL mapping of fire blight resistance in Malus xrobusta 5 after inoculation with different strains of Erwinia amylovora. Molecular Breeding 34: 217-230.

Yamamoto, T., Kimura, T., Saito, T., Kotobuki, K., Matsuta, N., Liebhard, R., Gessler, C., van de Weg, W.E. and Hayashi, T. 2004. Genetic linkage maps of japanese and european pears aligned to the apple consensus map. Acta Horticulturae 663: $51-56$.

Youssef, K., Roberto, S., Colombo, R., Canteri, M. and Elsalam, K. 2019. AcibenzolarS-methyl against Botrytis mold on table grapes in vitro and in vivo. Agronomy Science and Biotechnology 5: 52.

Ziadi, S., Poupard, P., Brisset, M., Paulin, J.-P. and Simoneau, P. 2001. Characterization in apple leaves of two subclasses of PR-10 transcripts inducible by acibenzolar-S-methyl, a functional analogue of salicylic acid. Physiological and Molecular Plant Pathology 59: 33-43. 


\begin{tabular}{|c|c|c|c|c|c|c|}
\hline Experiment & Treatment & Mean & Effectiveness ASM (\%) & cV & $h^{2}$ & Global $\mathbf{R}^{2}$ \\
\hline & water & $41.2 \pm 36.8$ & & $0.84[0.29]_{\mathrm{qT} 1-}$ & 0.94 & $81.9[65.1]_{\mathrm{qT} 1-}$ \\
\hline \multirow[t]{2}{*}{ Vi-B04_1 } & ASM & $18.9 \pm 26.4$ & 54 & $1.27[0.48]_{\mathrm{qT} 1-}$ & 0.91 & $70.2[53.8]_{\mathrm{qT1}}$ \\
\hline & water & $24.1 \pm 21.4$ & & 0.75 & 0.84 & 47.5 \\
\hline \multirow[t]{2}{*}{ Vi-Z14 } & ASM & $6.6 \pm 8.4$ & 73 & 0.88 & 0.71 & 15.0 \\
\hline & water & $6.2 \pm 2.4$ & & 0.27 & 0.70 & 35.0 \\
\hline Еa-1430_1 & ASM & $3.1 \pm 1.8$ & 50 & 0.34 & 0.63 & 33.1 \\
\hline
\end{tabular}

\section{Tables}

Table 1. Mean values ( \pm standard-deviation) of AUDPC, relative effectiveness of ASM, coefficient of variation of individual BLUPs $(\mathrm{CV})$, broad-sense heritability $\left(\mathrm{h}^{2}\right)$ and phenotypic variation explained by all detected resistance $\mathrm{QTLs}\left(\mathrm{global} \mathrm{R}^{2}\right)$ against scab $(\mathrm{V}$. inaequalis isolates EU-B04 and 09BCZ14; experiments Vi-B04_1 and Vi-Z14, respectively) and fire blight (E. amylovora isolate CFPB1430; experiment Ea-1430_1) in the TxF progeny. Values for the sub-population qT1- are indicated within brackets.

Effectiveness of ASM is computed as: (Mean-water - Mean-PRI)/Mean-water. 
Table 2. Parameters associated with the quantitative trait loci (QTLs) identified for disease resistance against scab (experiments ViB04_1, sub-population qT1-, and Vi-Z14) and fire blight (experiment Ea-1430_1) in the TxF progeny after water- or ASM-treatment.

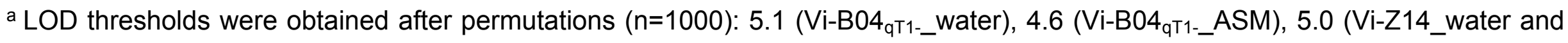
Vi-Z14_ASM), 4.7 (Ea-1430_water) and 4.6 (Ea-1430_ASM). Significant QTLs are shown in bold. Suggestive QTLs with LOD score between 3.0 and the LOD threshold are shown in italics. QTLs being insignificant in a condition but significant in another are shown in grey.

${ }^{b}$ position of 2-LOD support QTL confidence interval borders 


\begin{tabular}{|c|c|c|c|c|c|c|}
\hline Trait & Treatment & Linkage group & Position & LOD a & $\mathbf{R}^{2}$ & $\mathrm{Cl}^{\mathrm{b}}$ \\
\hline \multirow{9}{*}{ Vi-B04_1 1qT1- } & \multirow{5}{*}{ water } & T13 & 3.58 & 8.6 & 9.3 & $0.00-6.80$ \\
\hline & & F3 & 13.36 & 5.7 & 5.5 & $8.25-18.54$ \\
\hline & & F11 & 5.00 & 10.7 & 18.1 & $0.00-20.98$ \\
\hline & & $F 12$ & 25.99 & 3.0 & 3.7 & $20.46-31.56$ \\
\hline & & F17 & 18.92 & 12.4 & 29.0 & $16.52-27.35$ \\
\hline & \multirow{4}{*}{ ASM } & $\begin{array}{l}\text { T13 } \\
\text { F3 }\end{array}$ & $\begin{array}{c}3.58 \\
44.80\end{array}$ & $\begin{array}{l}0.3 \\
0.8\end{array}$ & - & $\begin{array}{l}- \\
-\end{array}$ \\
\hline & & F11 & 0.00 & 7.6 & 10.7 & $0.00-7.91$ \\
\hline & & $F 12$ & 19.28 & 4.0 & 5.1 & $10.83-24.43$ \\
\hline & & F17 & 18.00 & 21.2 & 39.9 & $16.52-20.90$ \\
\hline \multirow{9}{*}{ Vi-Z14 } & \multirow[t]{3}{*}{ water } & $\begin{array}{c}\text { T1 } \\
\text { T10 } \\
\text { T13 } \\
\text { F3 }\end{array}$ & $\begin{array}{c}45.03 \\
62.09 \\
3.18 \\
3.92\end{array}$ & $\begin{array}{c}9.4 \\
3.6 \\
10.9 \\
5.1\end{array}$ & $\begin{array}{c}10.7 \\
3.5 \\
10.1 \\
5.3\end{array}$ & $\begin{array}{c}39.01-\mathbf{5 2 . 8 9} \\
54.88-65.69 \\
\mathbf{0 . 0 0}-\mathbf{6 . 8 0} \\
\mathbf{0 . 0 0 - 9 . 0 3}\end{array}$ \\
\hline & & F11 & 5.53 & 7.8 & 7.9 & $0.00-20.98$ \\
\hline & & F17 & 18.92 & 9.1 & 10.7 & $14.18-27.35$ \\
\hline & \multirow{6}{*}{ ASM } & $\overline{T 1}$ & 36.61 & 1.7 & - & - \\
\hline & & T10 & 62.09 & 2.2 & - & - \\
\hline & & $T 13$ & 0.00 & 4.1 & 6.3 & $0.00-6.80$ \\
\hline & & F3 & 5.50 & 1.1 & - & - \\
\hline & & $F 11$ & 3.17 & 3.9 & 5.0 & $0.00-8.69$ \\
\hline & & F17 & 18.92 & 4.2 & 5.0 & $13.79-27.35$ \\
\hline \multirow{10}{*}{ Ea-1430_1 } & \multirow{5}{*}{ water } & T3 & 23.57 & 4.1 & 3.1 & $11.81-26.76$ \\
\hline & & T5 & 54.33 & 5.8 & 5.2 & $43.24-62.05$ \\
\hline & & F5 & 39.73 & 2.5 & - & - \\
\hline & & F7 & 69.46 & 18.4 & 20.1 & $67.10-71.42$ \\
\hline & & $F 15$ & 76.05 & 3.7 & 3.9 & $70.94-81.15$ \\
\hline & \multirow{5}{*}{ ASM } & T3 & 20.38 & 3.7 & 4.6 & $17.13-29.18$ \\
\hline & & T5 & 35.22 & 4.9 & 4.6 & $28.37-40.84$ \\
\hline & & F5 & 38.56 & 6.3 & 8.4 & $32.18-42.08$ \\
\hline & & F7 & 69.07 & 12.2 & 13.2 & $67.10-71.42$ \\
\hline & & $\mathrm{F} 15$ & 86.70 & 2.9 & - & - \\
\hline
\end{tabular}


Table 3. Interactions between significant and suggestive QTLs identified in Vi-B04_1 1 qT1- and Vi-Z14 experiments.

\begin{tabular}{|c|c|c|c|c|c|c|c|c|c|c|c|}
\hline \multirow[b]{2}{*}{ Trait } & \multirow[b]{2}{*}{ QTLs combination } & \multicolumn{5}{|c|}{ water } & \multicolumn{5}{|c|}{ ASM } \\
\hline & & AA:AA & AB:AA & $A A: A B$ & $A B: A B$ & F-value ${ }^{a}$ & AA:AA & AB:AA & $A A: A B$ & $A B: A B$ & F-value a \\
\hline Vi-B04_1 qT1- $^{-}$ & qF11:qF17 & 149.6 & 146.2 & 99.5 & 131.3 & $12.1^{* * *}$ & 94.7 & 93.2 & 49.0 & 70.0 & $8.9^{* *}$ \\
\hline \multirow{4}{*}{ Vi-Z14 } & $\mathrm{qT1}: \mathrm{qF} 3$ & 34.2 & 19.2 & 24.7 & 16.6 & $6.6^{*}$ & - & - & - & - & - \\
\hline & qT13:qF3 & 19.9 & 35.5 & 15.8 & 25.4 & $6.6^{*}$ & - & - & - & - & - \\
\hline & qT10:qF11 & 15.7 & 24.3 & 23.1 & 31.2 & 4.9 * & - & - & - & - & - \\
\hline & $\mathrm{qF} 11: \mathrm{qF} 17$ & 31.3 & 32.3 & 12.8 & 24.9 & 4.2 * & - & - & - & - & - \\
\hline
\end{tabular}

${ }^{a} \mathrm{~F}$-value of the variance analysis Fisher-test where stars represent the significance of the test at the risk of $0.05\left({ }^{*}\right), 0.01\left({ }^{* *}\right)$ or $\left.7740.005{ }^{* * *}\right)$. 
775 Figures Captions

776 Figure 1. Relationship between disease severity (BLUP estimates) for water- and

777

778

779

780

781

782

783

784

785

786

787

788

789

790

791

792

793

794

795

796

797

798

799

ASM-treated individuals of the TxF progeny in (A) Vi-B04_1, (B) Vi-Z14 and (C) Ea1430 experiments. Distributions of BLUPs are shown in the upper (water control) and right (ASM treatment) part of each graph where the complete population is represented in grey and the sub-population qT1- (i.e., individuals selected as not-carrying the resistance allele of the major QTL qT1) in green. The same color code is used in the graph where the green dots are superimposed on the grey dots. Control and parental genotypes are shown with triangles in orange (TN10-8), red (Fiesta) and black (Gala and Golden Delicious). Cor is the Pearson coefficient of correlation between water and ASM BLUPs. Values for the sub-population qT1- are indicated within brackets.

Figure 2. LOD score curves of QTLs involved in resistance against scab (Vi-B04_1 and $\mathrm{Vi}-\mathrm{Z14}$ ) for each treatment identified in the TxF progeny (upper part) and relative effects (rEffects) of these QTLs (lower part). Blue and orange colors represent respectively the water control and ASM treatment. LOD score thresholds are drawn as horizontal lines with the respective colors. In each rEffect plot, mean and standard deviation of each rEffect, calculated with bootstrapping, are represented by a point and a vertical bar respectively, with the respective blue and orange color for water-control and ASM-treatment respectively.

Figure 3. LOD score curves of QTLs involved in resistance against fire blight (Ea1430_1) for each treatment identified in the TxF progeny (upper part) and relative effects (rEffects) of these QTLs (lower part). Blue and orange colors represent respectively the water control and ASM treatment. LOD score thresholds are drawn as horizontal lines with the respective colors. In each rEffect plot, mean and standard deviation of each rEffect, calculated with bootstrapping, are represented by a point and 
Juliette Bénéjam

Plant Disease

800 a vertical bar respectively, with the respective blue and orange color for water-control 801 and ASM-treatment respectively. 


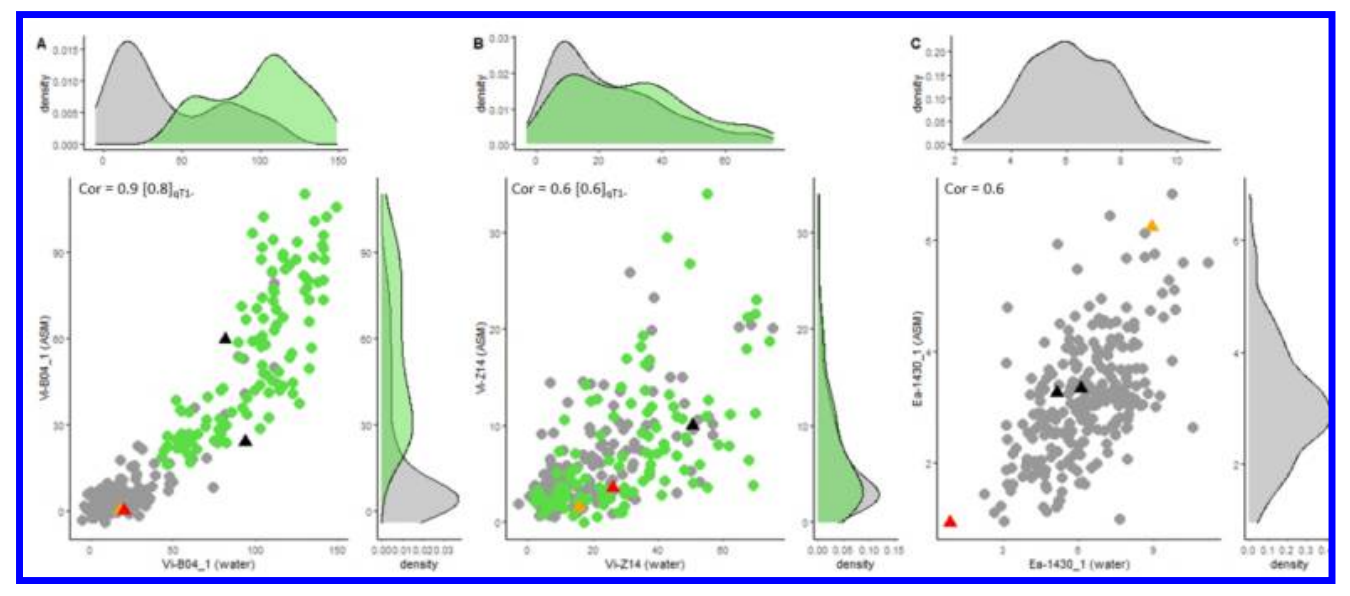

Figure 1. Relationship between disease severity (BLUP estimates) for water- and ASM-treated individuals of the TxF progeny in (A) Vi-B04_1, (B) Vi-Z14 and (C) Ea-1430 experiments. Distributions of BLUPs are shown in the upper (water control) and right (ASM treatment) part of each graph where the complete population is represented in grey and the sub-population qT1- (i.e., individuals selected as not-carrying the resistance allele of the major QTL qT1) in green. The same color code is used in the graph where the green dots are superimposed on the grey dots. Control and parental genotypes are shown with triangles in orange (TN10-8), red (Fiesta) and black (Gala and Golden Delicious). Cor is the Pearson coefficient of correlation between water and ASM BLUPs. Values for the sub-population qT1- are indicated within brackets. 


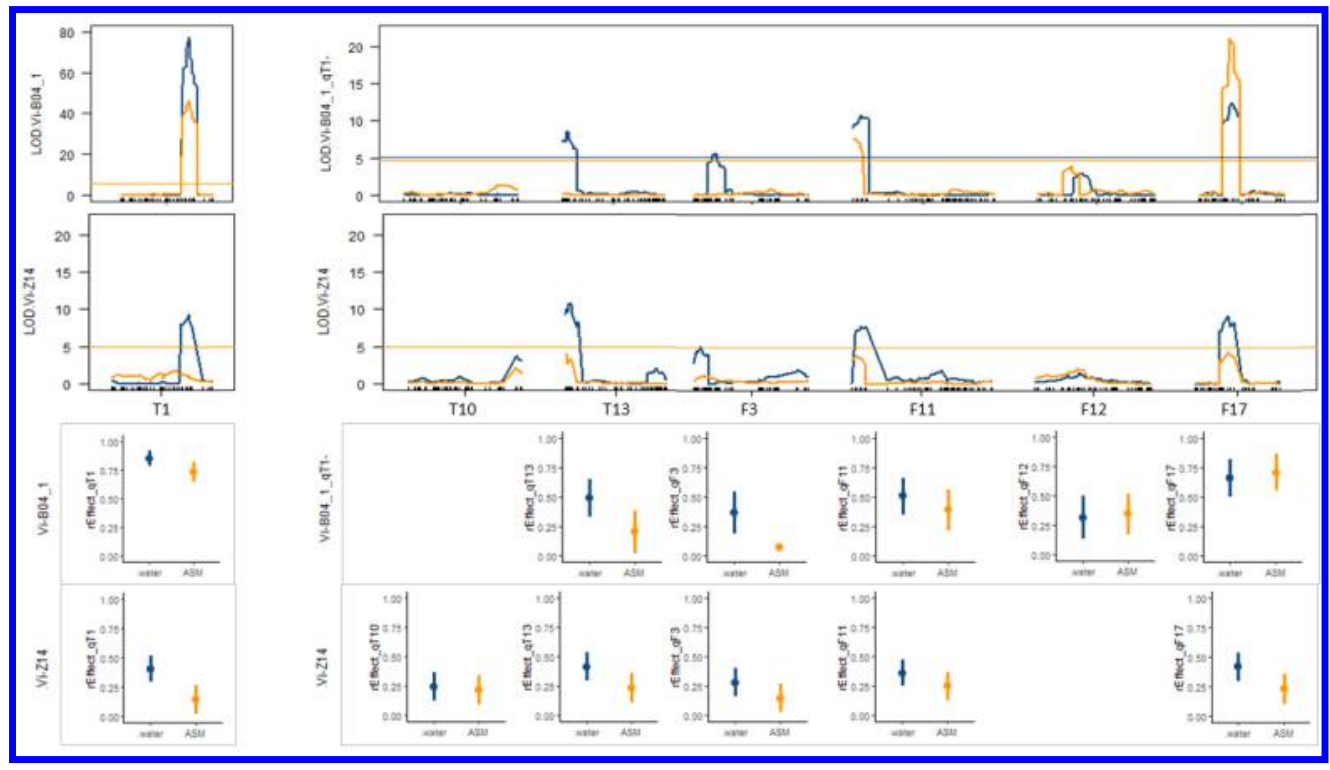

Figure 2. LOD score curves of QTLs involved in resistance against scab (Vi-B04_1 and Vi-Z14) for each treatment identified in the TXF progeny (upper part) and relative effects (rEffects) of these QTLs (lower part). Blue and orange colors represent respectively water control and ASM treatment. LOD score thresholds are drawn as horizontal lines with the respective colors. In each rEffect plot, mean and standard deviation of each rEffect, calculated with bootstrapping, are represented by a point and a vertical bar respectively, with the respective blue and orange color for water-control and ASM-treatment respectively. 


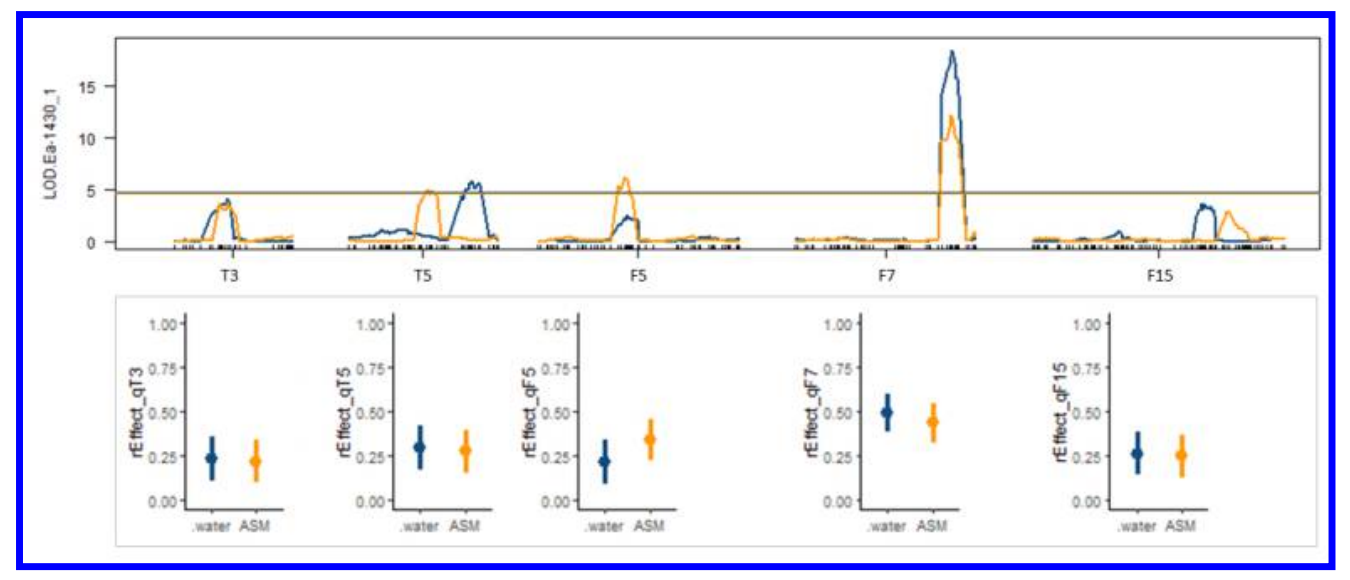

Figure 3. LOD score curves of QTLs involved in resistance against fire blight (Ea-1430_1) for each treatment identified in the TxF progeny (upper part) and relative effects (rEffects) of these QTLs (lower part). Blue and orange colors represent respectively water control and ASM treatment. LOD score thresholds are drawn as horizontal lines with the respective colors. In each rEffect plot, mean and standard deviation of each rEffect, calculated with bootstrapping, are represented by a point and a vertical bar respectively, with the respective blue and orange color for water-control and ASM-treatment respectively. 


\section{Supplementary Table S1. List of microsatellite markers added to the genetic map}

\begin{tabular}{|c|c|c|c|}
\hline Marker Name & Marker type & Linkage group & Reference \\
\hline $\mathrm{CH} 05 \mathrm{~g} 08$ & SSR & $\mathrm{T} 1$ & (Liebhard et al., 2002) \\
\hline $\mathrm{CH}-\mathrm{Vf} 1$ & SSR & $\mathrm{T} 1$ & (Vinatzer et al., 2004) \\
\hline HB04p & SSR & $\mathrm{T} 1$ & (Broggini et al., 2009) \\
\hline $\mathrm{Hi02c07}$ & SSR & $\mathrm{T} 1$ & (Silfverberg-Dilworth et al., 2006) \\
\hline $\mathrm{KA} 4 \mathrm{~b}$ & SSR & $\mathrm{T} 1$ & (Yamamoto et al., 2004) \\
\hline Md-Exp7 & SSR & $\mathrm{T} 1$ & (Costa et al., 2008) \\
\hline NZmsCN879773 & SSR & $\mathrm{T} 1$ & (Celton et al., 2009) \\
\hline Vf2ARD & SCAR & $\mathrm{T} 1$ & (Boudichevskaia et al., 2009) \\
\hline $\mathrm{CH} 02 \mathrm{~d} 08$ & SSR & F11 & (Liebhard et al., 2002) \\
\hline $\mathrm{CH} 04 \mathrm{~h} 02$ & SSR & $\mathrm{F} 11$ & (Liebhard et al., 2002) \\
\hline Rvi18SSR & SSR & $\mathrm{F} 11$ & (Soriano et al., 2014) \\
\hline $\mathrm{CH} 01 \mathrm{~h} 01$ & SSR & $\mathrm{F} 17$ & (Liebhard et al., 2002) \\
\hline $\mathrm{CH} 04 \mathrm{f0} 8$ & SSR & $\mathrm{F} 17$ & (Liebhard et al., 2002) \\
\hline $\mathrm{CH} 05 \mathrm{~g} 03$ & SSR & $\mathrm{F} 17$ & (Liebhard et al., 2002) \\
\hline GD96 & SSR & $\mathrm{F} 17$ & (Hokanson et al., 1998) \\
\hline Hi02f12 & SSR & $\mathrm{F} 17$ & (Silfverberg-Dilworth et al., 2006) \\
\hline $\mathrm{Hi03c05}$ & SSR & $\mathrm{F} 17$ & (Silfverberg-Dilworth et al., 2006) \\
\hline
\end{tabular}


Supplementary Table S2. Mean values ( \pm standard-deviation) of AUDPC, relative effectiveness of ASM, coefficient of variation of individual BLUPs (CV), broad-sense heritability $\left(\mathrm{h}^{2}\right)$ and phenotypic variation explained by all detected resistance $Q T L s\left(g l o b a l R^{2}\right)$ against scab $(V$. inaequalis isolate EU-B04; experiment Vi-B04_2) and fire blight (E. amylovora isolate CFPB1430; experiment Ea-1430_2) in the TxF progeny. Values for the sub-population qT1- are indicated within brackets. Effectiveness of ASM is computed as: (Mean-water - Mean-PRI)/Mean-water.

\begin{tabular}{|c|c|c|c|c|c|c|}
\hline Experiment & Treatment & Mean & Effectiveness ASM (\%) & CV & $\mathbf{h}^{2}$ & Global R² \\
\hline \multirow{3}{*}{ Vi-B04_2 } & water & $22.9 \pm 26.2$ & & $1.03[0.47]_{\mathrm{qT} 1}-$ & 0.89 & $56.1[68.8]_{\mathrm{qT} 1-}$ \\
\hline & ASM & $5.1 \pm 8.9$ & 78 & $1.62[0.59]_{\mathrm{qT} 1-}$ & 0.85 & $56.3[56.7]_{\mathrm{qT} 1-}$ \\
\hline & water & $4.2 \pm 2.5$ & & 0.30 & 0.51 & 30.2 \\
\hline Ea-1430_2 & ASM & $2 \pm 1.5$ & 52 & 0.43 & 0.56 & 26.1 \\
\hline
\end{tabular}


Supplementary Table S4. Parameters associated with the quantitative trait loci (QTLs) identified for disease resistance against scab (experiment Vi-B04_1, whole population) in the TxF progeny after water- or ASM-treatment.

\begin{tabular}{|c|c|c|c|c|c|c|}
\hline Trait & Treatment & Linkage group & Position & LOD $^{a}$ & $\mathbf{R}^{2}$ & $\mathrm{Cl}^{\mathrm{b}}$ \\
\hline \multirow{12}{*}{ Vi-B04_1 } & \multirow{6}{*}{ water } & T1 & 43.00 & 77.1 & 69.9 & $41.01-44.23$ \\
\hline & & T13 & 3.58 & 6.3 & 2.8 & $0.00-6.80$ \\
\hline & & F3 & 12.19 & 1.6 & & \\
\hline & & F11 & 6.00 & 8.9 & 7.7 & $0.00-20.98$ \\
\hline & & $F 12$ & 4.00 & 3.3 & 0.6 & $0.00-6.87$ \\
\hline & & F17 & 18.92 & 16.7 & 12.8 & $16.52-20.90$ \\
\hline & \multirow{6}{*}{ ASM } & $\mathbf{T 1}$ & 43.03 & 46.1 & 60.0 & $41.01-44.23$ \\
\hline & & $\mathrm{T} 13$ & 3.58 & 0.8 & & \\
\hline & & F3 & 1.96 & 0.3 & & \\
\hline & & $F 11$ & 4.75 & 4.3 & 6.9 & $0.00-20.98$ \\
\hline & & $\mathrm{F} 12$ & 19.28 & 2.3 & & \\
\hline & & F17 & 18.92 & 15.9 & 24.9 & $16.52-20.90$ \\
\hline
\end{tabular}

a LOD thresholds were obtained after permutations $(\mathrm{n}=1000)$ : 5.5 (Vi-B04_water) and 5.4 (Vi-B04_ASM). Significant QTLs are shown in bold. Suggestive QTLs with LOD score between 3.0 and the LOD threshold are shown in italics. QTLs being insignificant in a condition but significant in another are shown in grey.

${ }^{\mathrm{b}}$ position of 2-LOD support QTL confidence interval borders 


\section{Page 39 of 45}

Supplementary Table S5. Parameters associated with the quantitative trait loci (QTLs) identified for disease resistance against scab (experiment Vi-B04_2) and fire blight (experiment Ea-1430_2) in the TxF progeny after water- or ASM-treatment.

a LOD thresholds were obtained after permutations ( $\mathrm{n=1000):} 4.70$ (Vi-B04_water); 4.50 (Vi-B04_ASM); 5.82 (Vi-B04qT1-_water); 7.33 (Vi-B04qT1_ASM); 4.77 (Ea-1430_water); 5.27 (Ea_1430_ASM). Significant QTLs are shown in bold. Suggestive QTLs with LOD score between 3.0 and the LOD threshold are shown in italics. QTLs being insignificant in a condition but significant in another are shown in grey.

${ }^{b}$ position of 2-LOD support QTL confidence interval borders 


\begin{tabular}{|c|c|c|c|c|c|c|}
\hline Trait & Treatment & Linkage group & Position & $\operatorname{LOD}^{a}$ & $\mathbf{R}^{2}$ & $\mathrm{Cl}^{\mathrm{b}}$ \\
\hline \multirow{12}{*}{ Vi-B04_2 } & \multirow{6}{*}{ water } & T1 & 43.03 & 35.2 & 40.42 & $41.01-44.23$ \\
\hline & & $\mathrm{T} 13$ & 44.94 & 2.1 & & \\
\hline & & F3 & 13.36 & 1.6 & & \\
\hline & & F11 & 5.53 & 5.3 & 4.99 & $0.00-7.91$ \\
\hline & & $F 12$ & 25.99 & 3.9 & 3.54 & $0.00-46.60$ \\
\hline & & F17 & 18.92 & 14.4 & 13.30 & $16.52-20.90$ \\
\hline & \multirow{6}{*}{ ASM } & T1 & 43.03 & 34.5 & 48.1 & $41.01-45.43$ \\
\hline & & T13 & 0.40 & 1.1 & & \\
\hline & & F3 & 22.88 & 2.1 & & \\
\hline & & F11 & 5.53 & 2.9 & & \\
\hline & & $\mathrm{F} 12$ & 25.99 & 2.2 & & \\
\hline & & F17 & 18.92 & 12.5 & 21.8 & $16.52-20.90$ \\
\hline \multirow{10}{*}{ Vi-B04_2_qT1- } & \multirow{5}{*}{ water } & $T 13$ & 0.40 & 5.4 & 12.7 & $0.00-6.80$ \\
\hline & & F3 & 13.36 & 4.3 & 4.9 & $9.81-18.54$ \\
\hline & & $F 11$ & 20.98 & 5.2 & 13.8 & $8.69-26.31$ \\
\hline & & $F 12$ & 25.99 & 4.9 & 11.2 & $20.46-31.56$ \\
\hline & & F17 & 18.92 & 14.3 & 37.3 & $16.52-22.48$ \\
\hline & \multirow{5}{*}{ ASM } & $T 13$ & 0.40 & 3.3 & 3.3 & $0.00-6.80$ \\
\hline & & F3 & 13.36 & 3.9 & 5.4 & $8.25-18.54$ \\
\hline & & $F 11$ & 26.31 & 5.4 & 6.9 & $20.98-33.17$ \\
\hline & & $F 12$ & 24.82 & 3.7 & 7.9 & $20.46-31.56$ \\
\hline & & F17 & 18.92 & 19.2 & 33.7 & $16.52-20.90$ \\
\hline \multirow{18}{*}{ Ea-1430_2 } & \multirow{9}{*}{ water } & T1 & 7.64 & 1.5 & - & - \\
\hline & & T3 & 27.16 & 5.0 & 9.4 & $21.57-32.02$ \\
\hline & & T5 & 63.66 & 4.1 & 6.3 & $57.93-65.65$ \\
\hline & & $\mathrm{T} 7$ & 3.19 & 1.1 & & \\
\hline & & $T 15$ & 29.70 & 3.6 & 9.3 & $21.68-32.50$ \\
\hline & & F1 & 29.65 & 1.1 & & \\
\hline & & F5 & 47.65 & 4.4 & 7.4 & $42.08-61.62$ \\
\hline & & F7 & 65.12 & 1.8 & & \\
\hline & & $F 15$ & 86.70 & 3.2 & 4.2 & $81.15-92.65$ \\
\hline & \multirow{9}{*}{ ASM } & $T 1$ & 0.40 & 3.3 & 5.1 & $0.00-58.27$ \\
\hline & & Т3 & 15.93 & 1.3 & & \\
\hline & & T5 & 49.55 & 5.1 & 5.3 & $43.24-53.14$ \\
\hline & & $T 7$ & 23.12 & 4.1 & 4.5 & $15.73-29.10$ \\
\hline & & T15 & 40.23 & 2.5 & & \\
\hline & & F1 & 26.12 & 5.9 & 7.0 & $15.4-31.63$ \\
\hline & & F5 & 47.65 & 3.9 & 9.1 & $42.08-61.62$ \\
\hline & & F7 & 63.13 & 1.6 & & \\
\hline & & F15 & 96.57 & 1.1 & - & . \\
\hline
\end{tabular}


Supplementary Table S6. Interactions between significant and suggestive QTLs identified in Vi-B04_2, Vi-B04_2qT1-and Ea-1430_2 experiments.

\begin{tabular}{|c|c|c|c|c|c|c|c|c|c|c|c|}
\hline \multirow[b]{2}{*}{ Trait } & \multirow[b]{2}{*}{ QTLs combination } & \multicolumn{5}{|c|}{ water } & \multicolumn{5}{|c|}{ ASM } \\
\hline & & AA:AA & $A B: A A$ & $A A: A B$ & $A B: A B$ & F-value a & AA:AA & AB:AA & $A A: A B$ & $A B: A B$ & F-value a \\
\hline Vi-B04_2qT1- & $\begin{array}{l}\text { qT13:qF11 } \\
\text { qT13:qF17 } \\
\text { qF12:qF17 }\end{array}$ & $\begin{array}{l}56.3 \\
78.1 \\
90.1\end{array}$ & $\begin{array}{l}65.1 \\
97.2 \\
83.7\end{array}$ & $\begin{array}{l}64.6 \\
53.0 \\
65.8\end{array}$ & $\begin{array}{l}84.3 \\
63.7 \\
47.9\end{array}$ & $\begin{array}{l}9.0^{* *} \\
7.7^{* *} \\
5.0^{*}\end{array}$ & $\begin{array}{l}- \\
- \\
-\end{array}$ & $\begin{array}{l}- \\
- \\
-\end{array}$ & $\begin{array}{l}- \\
- \\
-\end{array}$ & - & - \\
\hline Ea-1430_2 & $\begin{array}{l}\text { qT3:qT15 } \\
\text { qT5:qF5 } \\
\text { qT1:qF5 } \\
\text { qF1:qF5 }\end{array}$ & $\begin{array}{l}4.0 \\
4.0 \\
- \\
-\end{array}$ & $\begin{array}{l}5.0 \\
3.7 \\
- \\
-\end{array}$ & $\begin{array}{l}3.8 \\
5.0 \\
- \\
-\end{array}$ & $\begin{array}{l}3.9 \\
4.1 \\
- \\
-\end{array}$ & $\begin{array}{c}10.5^{* *} \\
7.0^{* *} \\
- \\
-\end{array}$ & $\begin{array}{c}- \\
- \\
1.8 \\
1.9\end{array}$ & $\begin{array}{l}- \\
- \\
1.8 \\
1.8\end{array}$ & $\begin{array}{l}- \\
- \\
2.4 \\
2.4\end{array}$ & $\begin{array}{l}- \\
- \\
1.9 \\
1.8\end{array}$ & $\begin{array}{c}- \\
- \\
4.8 * \\
4.0 *\end{array}$ \\
\hline
\end{tabular}

${ }^{a}$ F-value of the variance analysis Fisher-test where stars represent the significance of the test at the risk of $0.05\left({ }^{\star}\right), 0.01\left({ }^{\star \star}\right)$ or $0.005\left({ }^{\star \star \star}\right)$. 
Supplementary Figure S1. Relationship between disease severity (BLUP estimates) for waterand ASM- treated individuals of the TxF progeny in (A) Vi-B04_2 and (B) Ea-1430_2 experiments. Distributions of BLUPs are shown in the upper (water control) and right (ASM treatment) part of each graph where the complete population is represented in grey and the sub-population qT1- (i.e., individuals selected as not-carrying the resistance allele of the major QTL qT1) in green. The same color code is used in the graph where the green dots are superimposed on the grey dots. Control and parental genotypes are shown with triangles in orange (TN10-8), red (Fiesta) and black (Gala and Golden Delicious). Cor is the Pearson coefficient of correlation between water and ASM BLUPS. Value for the sub-population qT1- is indicated within brackets.

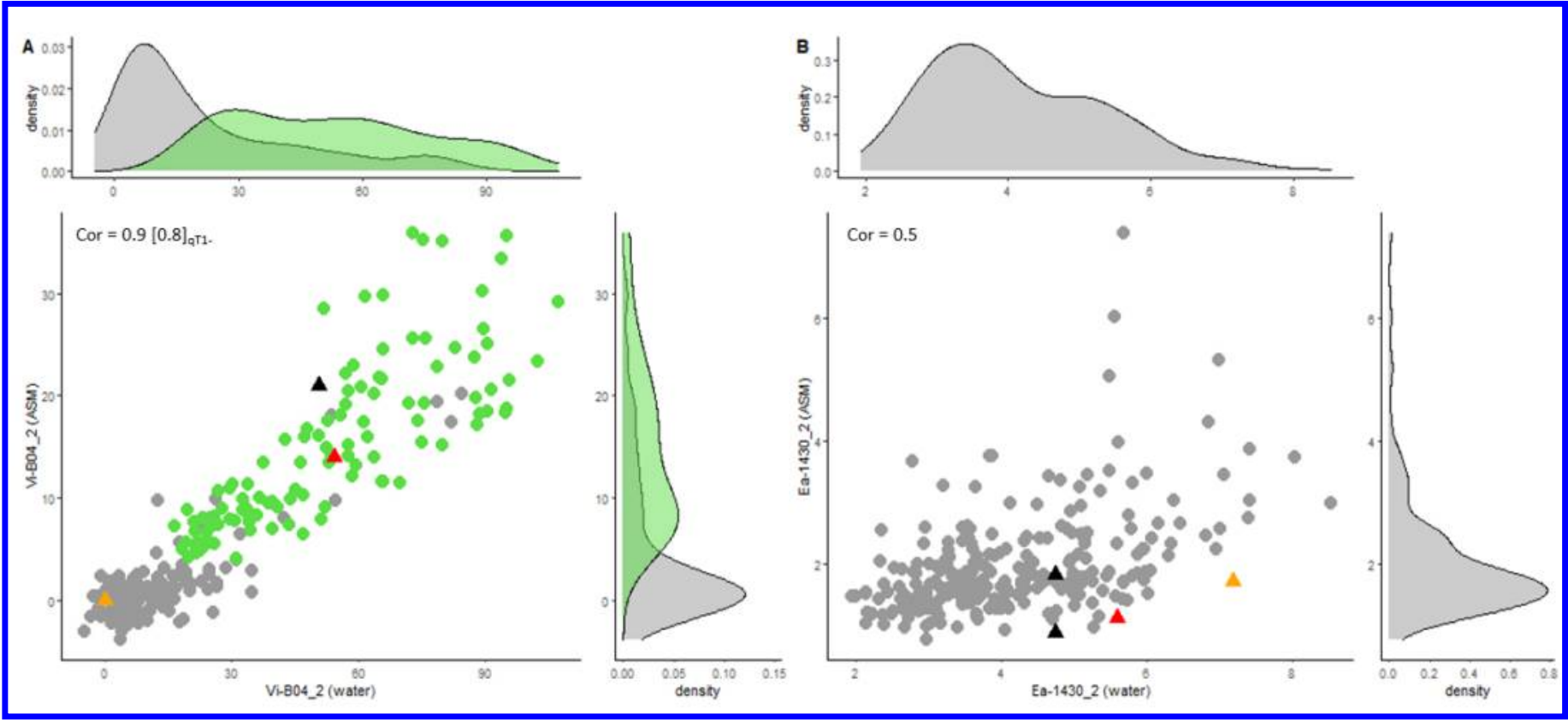


Supplementary Figure S2. LOD score curves of QTLs involved in resistance against scab (ViB04_2) for each treatment identified in the TxF progeny (upper part) and relative effects (rEffects) of these QTLs (lower part). Blue and orange colors represent respectively the water control and ASM treatment. LOD score thresholds are drawn as horizontal lines with the respective colors. In each rEffect plot, mean and standard deviation of each rEffect, calculated with bootstrapping, are represented by a point and a vertical bar respectively, with the respective blue and orange color for water-control and ASM-treatment respectively.

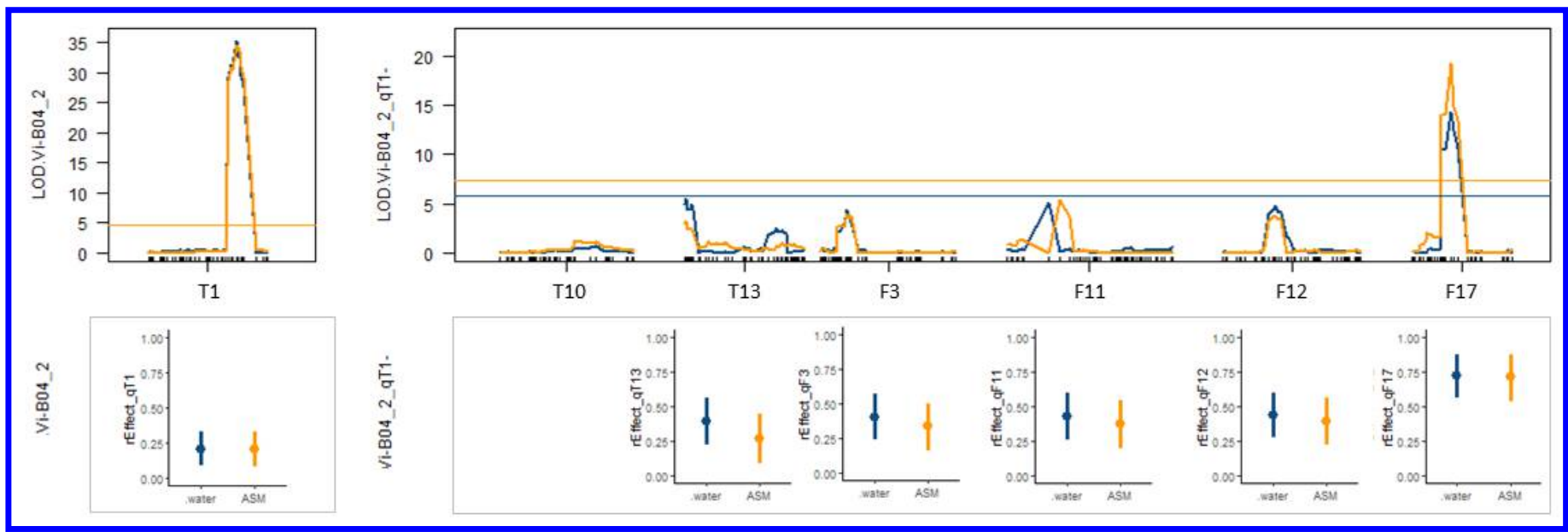


Supplementary Figure S3. LOD score curves of QTLs involved in resistance against fire blight (Ea-1430_2) for each treatment identified in the TxF progeny (upper part) and relative effects (rEffects) of these QTLs (lower part). Blue and orange colors represent respectively the water control and ASM treatment. LOD score threshold are drawn as horizontal lines with the respective colors. In each rEffect plot, mean and standard deviation of each rEffect, calculated with bootstrapping, are represented by a point and a vertical bar respectively, with the respective blue and orange color for water-control and ASM-treatment respectively.

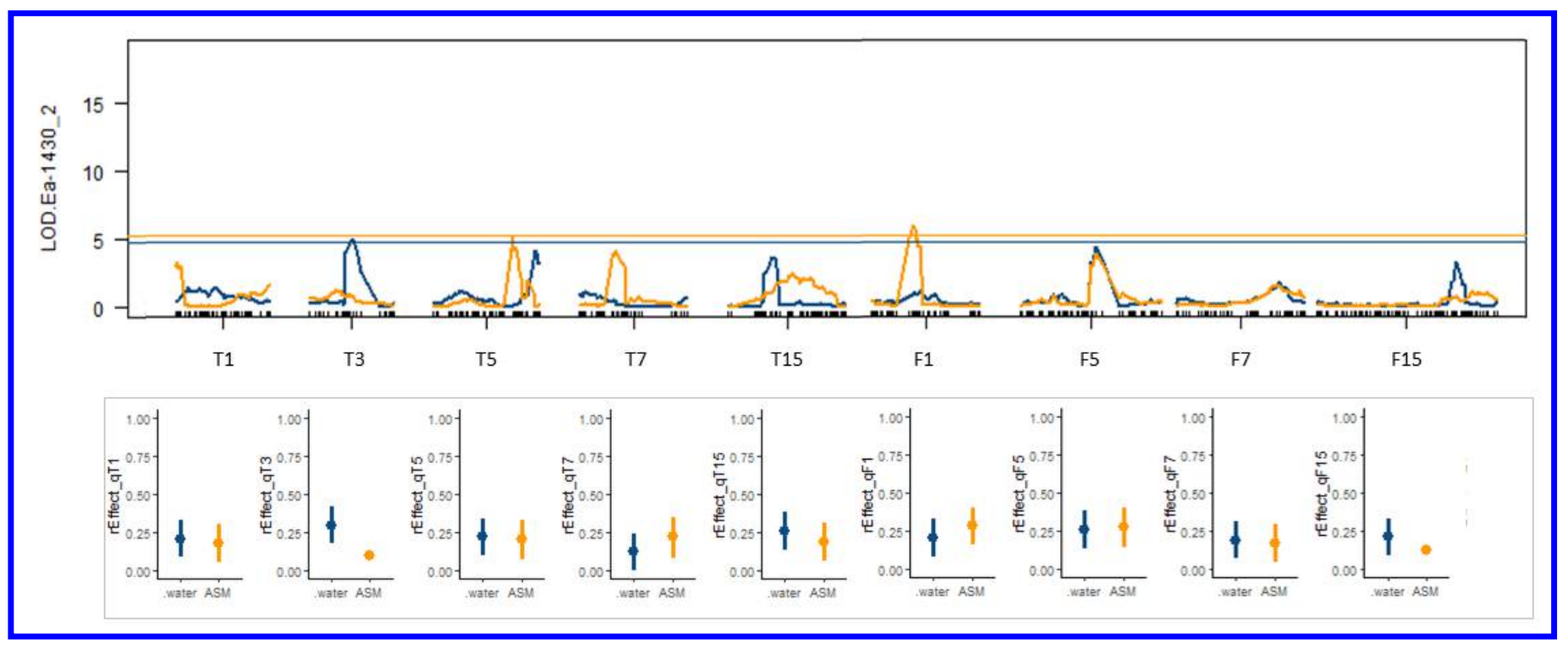


Supplementary Table S3. Summary of the genetic map of the TxF progeny. For each linkage group of each parent, SNP markers are ordered according to their genetic position given in centimorgan (cM). 